\title{
El trabajo de las mujeres voluntarias en el Laboratorio de Farmacia Militar de Santiago de Compostela (1936-1939)
}

\author{
Brasa Arias B. ${ }^{1}$, Landín Pérez M. ${ }^{2}$ \\ Sanid. mil. 2011; 67 Suplemento (1): 131-134; ISSN: 1887-8571
}

\begin{abstract}
RESUMEN
Este trabajo trata sobre el Laboratorio de Farmacia Militar que, durante la guerra civil española, existió en la Facultad de Farmacia de Santiago de Compostela y que contó con la colaboración de mujeres voluntarias para producir los medicamentos necesarios para el frente. El hecho de que una institución académica se transformase en un centro militar, reintegrando a su platilla docente en el ejército y fabricando análogos de fármacos que escaseaban por la situación de guerra, confiere al tema un particular interés. La participación de las jóvenes compostelanas que sirvieron como mano de obra en este Laboratorio Militar nos permite analizar el papel de las mujeres al servicio del ejército en la retaguardia, en una labor tan importante como silenciada por los historiadores. De este Laboratorio de Farmacia Militar, de su producción, de la plantilla y de los hechos con él relacionados versa este trabajo de investigación.
\end{abstract}

PALABRAS CLAVE: Facultad; Farmacia; Santiago de Compostela; Guerra Civil española; Laboratorio Farmacia Militar; Voluntarias.

The work of volunteer women at the Military Pharmaceutical Laboratory of Santiago de Compostela (1936-1939) SUMMARY:

This work is about the Military Pharmaceutical Laboratory placed at the Faculty of Pharmacy of University of Santiago de Compostela during the Spanish civil war and the help of volunteer women to produce the necessary drugs for the Franco's Army. The fact that an academic institution would become a military center, restoring his teaching staff in the Army and manufacturing the necessary drugs for the particular war situation, gives the subject a great interest. Local young women participation as workers in such as labor in the Military Lab allows us to analyze the role of women in the Army service in the rear. An important subject often silenced by historians. The Military Pharmaceutical Laboratory, its production, its staff and the facts related to it is the goal of this research.

KEY WORDS: Faculty; Pharmacy; Santiago de Compostela; Spanish Civil War; Military Pharmaceutical Laboratory; Volunteer women.

\section{INTRODUCCIÓN}

El 18 de julio de 1936 varios generales del ejército español se sublevaron para derrocar del poder al recién formado gobierno republicano. Este pronunciamiento militar se vio secundado por las zonas de Galicia, sur de Andalucía, Aragón y Navarra. El resto del país permaneció fiel a la II República, de modo que se desencadenó una guerra civil por el control del gobierno de la nación que duró casi tres años.

Pese al inicial pacto internacional de no intervencionismo, ambos bandos se vieron auxiliados en mayor o menor medida por fuerzas extranjeras atendiendo a sus filias políticas: el ejército nacional por las Brigadas Internacionales y la Unión Soviética, y el autodenominado ejército nacional por Italia y la Alemania nazi.

Dentro de las diferentes concepciones de Estado y sociedad que los dos bandos tenían, el papel asignado a las mujeres durante el conflicto difería también notablemente. En el bando republicano las mujeres no sólo colaboraron desde la retaguardia, sino que llegaron a intervenir directamente en el combate, aunque de forma minoritaria, como milicianas, para defender los logros sociales alcanzados

${ }^{1}$ Doctora en Historia de la Farmacia por la Universidad de Santiago.

${ }^{2}$ Profesora titular de Historia de la Farmacia. Universidad de Santiago de Compostela. Facultad de Farmacia. Departamento de Farmacia y Tecnología Farmacéutica.

Dirección para correspondencia: Dra. Landín Pérez. Departamento de Farmacia y Tecnología Farmacéutica. Facultad de Farmacia. Campus Vida. C.P.: 15782. Santiago de Compostela. Pabellón C, primer piso. beatrizbrasa@gmail.com; m.landin@usc.es

Recibido: 28 de junio de 2010

Aceptado: 8 de noviembre de 2010 por y para su género durante la II República: derecho al voto, mejora de la educación pública para las niñas, facilidades laborales, etc. En el bando sublevado las mujeres trabajaron en la retaguardia organizadas en el Servicio Social, coordinado por la Sección Femenina de Falange Española, principalmente en talleres de costura, confeccionando ropa para los soldados, así como en labores de tipo humanitario.

En ambos casos el trabajo de las mujeres como colaboradoras de los ejércitos, aunque con sus matices ideológicos, era similar, puesto que principalmente se dedicaron a actividades de voluntariado con niños y ancianos, confección de prendas para el ejército, auxilio sanitario como enfermeras y mano de obra en fábricas que habían perdido sus plantillas masculinas por haberse éstos alistado en los ejércitos combatientes. Este punto tuvo más aceptación dentro del bando republicano debido principalmente a la mayor industrialización de esas zonas (Madrid, Cataluña, País Vasco).

El trabajo de estas mujeres a las que les tocó participar de esta manera en la guerra, sólo por el hecho de haber quedado de un lado u otro de las líneas de combate, fue igualmente valioso para sus ejércitos. Sin embargo, la Historia escrita por hombres ha relegado al olvido la importancia que estas mujeres tuvieron en una sociedad en guerra. En el caso de las milicianas, ni siquiera en su propio bando encontraron respeto y aceptación por parte de sus compañeros y su gobierno; mientras que el trabajo de las jóvenes del Servicio Social fue valorado tan solo parcialmente y en menor medida que el trabajo masculino.

La investigación sobre la que se ha elaborado este trabajo nos ha llevado a conocer una pequeña historia dentro de la Historia. Se 
trata del trabajo singular que un grupo de jóvenes mujeres llevaron a cabo en una ciudad de provincias española durante los años de la guerra civil para ayudar a uno de los ejércitos que en ella participaron. La ciudad era Santiago de Compostela, el trabajo tuvo lugar en el Laboratorio de Farmacia Militar de la Facultad de Farmacia y el bando al que suministraban los medicamentos que producían era el ejército sublevado liderado por el general Franco.

\section{LA GUERRA CIVIL ESPAÑOLAY SU RELACIÓN CON LA PRODUCCIÓN DE MEDICAMENTOS PARA EL EJÉRCITO (1936-1939)}

Con la numerosa sucesión de nuevas síntesis de principios activos en el laboratorio que desde mediados del siglo XIX venía aconteciendo principalmente en Europa ${ }^{1}$, se asistía a la progresiva transformación de la profesión farmacéutica de manera que los boticarios dejaron de ser los fabricantes de medicamentos -el número de fórmulas magistrales elaboradas en las farmacias era de cada vez menor-para convertirse en dispensadores de los nuevos específicos procedentes de las florecientes industrias farmacéuticas. El hecho de que éstas se encontrasen fundamentalmente fuera de nuestras fronteras, sobre todo en Alemania, Francia e Inglaterra, hizo que la mayoría de los medicamentos consumidos por la población española en estos años procediese del extranjero ${ }^{2}$.

La falta de desarrollo de la industria farmacéutica española y la importante dependencia que existía de la producción de medicamentos extranjeros, tuvo como consecuencia que, una vez estallada la guerra civil española, fuese necesario habilitar espacios donde fabricar productos farmacéuticos para atender a la extraordinaria demanda que el conflicto armado había provocado.

Esta circunstancia tuvo un mayor impacto en los territorios que desde el inicio de la guerra quedaron bajo dominio de los sublevados. La escasa industria farmacéutica que en el primer tercio de siglo existía en España se concentraba, fundamentalmente, en Madrid y Cataluña, que desde un principio permanecieron del lado de la República. De manera que el bando nacional se vio, desde el comienzo de la contienda, con recursos sanitarios de tipo farmacéutico muy limitados y sin posibilidades, en un principio, de obtener una producción a gran escala, tal y como demandaba la situación.

Por ello, mientras en la España republicana pudieron acceder a las fábricas de medicamentos para producir fármacos para el ejército, en el bando contrario se buscaron alternativas como la

\footnotetext{
${ }^{1}$ En 1828 Friedrich Wöhler sintetizó la urea; el ácido acetilsalicílico fue sintetizado por primera vez por Charles Frédéric Gerhardt en 1853 y luego en forma de sal por Hermann Kolbe en 1859. A partir de estos nuevos descubrimientos y de la mejora en las técnicas de síntesis y purificación de principios activos pudieron obtenerse en los laboratorios moléculas empleadas para la fabricación de medicamentos por la industria farmacéutica. En NICOLAOU, K.C. y MONTAGNON, T. Molecules that changed the world: a brief history of the art and science of synthesis and its impact on society. Weinheim: Wiley-VCH, 2008. ${ }^{2}$ En su trabajo acerca de la industria farmacéutica española el profesor Raúl Rodríguez Nozal apunta que, en 1883, el 70\% de las ventas brutas realizadas por los farmacéuticos españoles correspondía a medicamentos extranjeros. En RODRÍGUEZ NOZAL, R. «Orígenes, desarrollo y consolidación de la industria farmacéutica española», $A s$ clepio - Vol. LII-1-2000, p.142.
}

creación de estos espacios allá donde la infraestructura fuese más favorable.

Pocos días después de que estallase la guerra civil española, el 20 de agosto de $1936^{3}$, y hasta su conclusión en abril de 1939, la Facultad de Farmacia de la Universidad de Santiago de Compostela funcionó como un laboratorio de farmacia militar en el que se produjeron medicamentos y material de cura para el frente.

\section{LA FARMACIA MILITAR ESPAÑOLA DURANTE LA GUERRA CIVIL (1936-1939)}

El siguiente párrafo explica claramente todas las funciones que deben desarrollar los farmacéuticos militares:

«Siendo misión principal de los Servicios Farmacéuticos Militares el proporcionar a las tropas todos aquellos elementos de naturaleza químico-farmacéutica que les son necesarios para conservar o recuperar la salud, la función básica del Farmacéutico del Ejército, de la cual derivan todas sus demás actividades, consiste en el Abastecimiento de los indicados elementos, servicio que abarca las siguientes facetas funcionales: Fabricación, Elaboración, Recuperación y Adquisición [...] Sobre esta base descansa, a su vez, toda una gama de otras funciones o servicios que integran la misión farmacéutica militar: Dispensación, Suministro, Tratamiento, Análisis, Desinfección, Esterilización, Depuración y Regeneración» ${ }^{4}$.

Previo al estallido de la guerra, la Farmacia Militar española estaba totalmente desarrollada y diferenciada ${ }^{5}$ dentro de la Sanidad Militar y con una estructura organizada en torno al Laboratorio y Parque Central de Farmacia Militar en Madrid. En 1931 existían en España 59 farmacias militares: 38 eran farmacias de hospital y 21 farmacias de plaza militar ${ }^{6}$. Las farmacias de plaza eran aquellas ubicadas en cada división orgánica militar y tenían por función suministrar medicamentos y productos sanitarios a las tropas allí destacadas. Dentro de las mismas, se incluían las farmacias centrales divisionarias, encargadas de coordinar y llevar a cabo estas tareas. Cuando la población era elevada, se creaba otra farmacia de plaza en el mismo lugar para auxiliar a las centrales divisionarias en sus cometidos.

El personal militar farmacéutico que estaba en plantilla constaba de cuatro coroneles, quince teniente-coroneles, 28 comandantes, 57 capitanes y 19 tenientes. Un total de 123 hombres de los que 57 quedaron en zona republicana y 66 en la sublevada ${ }^{7}$ dependiente del gobierno de Burgos-sede del gobierno del general Franco-. Esto aconteció con relativa rapidez, tal como indica Luis Gómez

${ }^{3}$ MAIZ ELEIZEGUI, L. «Labor realizada en el primer año por el Laboratorio Militar de Santiago», El Compostelano de 21 de agosto de 1937. ${ }^{4}$ PEÑA TORREA, F.: El servicio de farmacia del Ejército Nacional durante la Guerra de Liberación. Su organización, funcionamiento y enseñanzas que se deducen, Madrid, 1941, p. 105.

${ }^{5}$ Así lo apunta Guillermo Folch: «Con orgullo podemos decir que los primeros atisbos de una organización farmacéutica militar son españoles, y que la Farmacia Militar española se adelantó centurias a las organizaciones castrenses de otros países... En los Ejércitos españoles, la separación de la Medicina y la Farmacia se halla por vez primera en tiempo de la dinastía de los Beni-Omeyas, que fue la que levantó los primeros cimientos de la Farmacia Militar española». FOLCH JOUS, G.: Historia de la Farmacia. Madrid, 1972, pp. 407 y 408

${ }^{6}$ GÓMEZ RODRÍGUEZ, L.: La evolución del servicio farmacéutico militar español en el siglo XX, Madrid, 1989, p.101.

${ }^{7}$ Ibídem, p.318. 
Rodríguez en su tesis doctoral ${ }^{8}$, en la que se señala que en el verano de 1937, un año después de comenzada la guerra, ambos ejércitos disponían de director de Servicios Farmacéuticos, jefes de Servicios Farmacéuticos con sus respectivos cuerpos de ejército y algunas divisiones. Además, pese a los problemas iniciales provocados por la división del país, cada ejército disponía en este corto periodo de tiempo, de un Parque Farmacéutico con sus correspondientes laboratorios y farmacias militares anexas, que habían dado respuesta a la demanda de medicamentos, productos sanitarios y equipos de análisis en los primeros meses de batalla. Un año después, en 1938, la organización era total en todos los escalafones.

El levantamiento militar dividió el país en dos zonas bien diferenciadas, con una escasa y complicada comunicación entre ellas. Esto repercutió directamente en el acceso a los medicamentos que por aquel entonces se fabricaban en España. Se desarticularon las redes de distribución de la industria farmacéutica, presente sobre todo en Cataluña y Madrid, y se restringieron los suministros de materias primas y combustibles.

En los primeros meses de combate, el ejército sublevado comenzó a notar la carestía de medicamentos y de material de cura debido a que la escasa industria farmacéutica existente en España en la época, la mayor parte de las fábricas de tejidos con los que elaborar vendas, así como el único establecimiento farmacéutico-militar de fabricación de medicamentos -el Laboratorio-Parque de Sanidad Militar de Madrid- habían quedado en zona republicana ${ }^{9}$

El Farmacéutico Mayor del Estado Mayor del Ejército, el general Francisco Peña Torrea, señala en su obra ${ }^{10}$ El servicio de farmacia del Ejército Nacional durante la Guerra de Liberación, en la que resume los tres años de guerra civil desde el punto de vista de la farmacia militar, que en un principio el ejército sublevado se abasteció de los medicamentos y material de cura de las farmacias militares correspondientes a su zona: Sevilla, Zaragoza, Burgos, Valladolid y A Coruña. Las existencias en estas plazas eran ya escasas, puesto que se encontraban al comienzo del tercer trimestre del año económico y todavía no se habían recibido las partidas correspondientes desde el Laboratorio-Parque Central de Madrid. Obviamente, este material no llegó a recibirse y por lo tanto se habilitaron como Laboratorio-Parque de Farmacia Militar, las Farmacias Militares de Valladolid -en octubre de 1936-, Burgos, Zaragoza y A Coruña. Esta última, contaba al comenzar la guerra con existencias de medicamentos para seis meses de servicio normal, incluyendo las farmacias militares de toda Galicia.

Finalmente, los Parques Farmacéuticos que organizaron los suministros de medicamentos y productos sanitarios durante la guerra en la zona sublevada fueron cinco: Valladolid, Sevilla, Zaragoza, Burgos y Calatayud.

La situación exigía la fabricación del propio material farmacéutico si se pretendía dar respuesta, con el menor coste económico posible, a las necesidades de una maquinaria bélica que ya se había puesto en marcha. Así lo dejaba claro el general Peña Torrea en 1941:

«Por lo que respectaba al Ejército nacional, y debido a la escasez de industria químico-farmacéutica en la zona redimida del yugo marxista, era ello de grandísima importancia, no sólo por la economía de precios que se lograba en lo fabricado o elaborado, sino también por lo que evitaba de ser tributarios del extranjero, cosa

\footnotetext{
${ }^{8}$ Ibídem, pp. 333-335.

${ }^{9}$ Ibídem, p. 337.

${ }^{10}$ PEÑA TORREA, F. (1941), p. 35.
}

muy conveniente en las circunstancias graves en que se iniciaba y desarrollaba la guerra» ${ }^{11}$.

La obra de Peña Torrea, salvando su excesiva retórica y del tono triunfalista propio del sector social que acababa de ganar una guerra y ostentaba el poder absoluto de los vencedores, es una excelente fuente de información sobre la estructuración del servicio de farmacia militar del ejército llamado nacional durante la contienda y la participación de los improvisados laboratorios de producción de medicamentos, como el que se instaló en la Facultad de Farmacia de Santiago de Compostela.

Una vez agotados los primeros recursos del ejército en la zona sublevada, se recurrió a la adquisición de sueros antitetánicos y antigangrenosos en farmacias civiles y centros y almacenes de productos químico-farmacéuticos existentes en las provincias. A través de farmacéuticos particulares se compraron medicamentos en el extranjero, si bien esta actividad fue minoritaria, debido a la dificultad de paso existente en las fronteras de los países vecinos ${ }^{12}$. De Italia, Irlanda, Alemania -países que apoyaron al bando sublevado- llegó ayuda en forma de productos y especialidades, además de poner a disposición del ejército franquista las existencias que en aquel momento había en los almacenes de las distintas casas comerciales localizadas en zona afecta al levantamiento militar ${ }^{13}$.

La Cruz Roja Internacional acordó, tanto con el gobierno republicano de Madrid, como con la Junta Nacional de Burgos suministrar material sanitario a ambos bandos. De este modo, a partir de septiembre de 1936 se recibieron anestésicos, sueros, vacunas, estupefacientes, vitaminas, material de cura, insulina, etc ${ }^{14}$.

\section{LA FACULTAD DE FARMACIA, SEDE DEL LABORATORIO DE FARMACIA MILITAR DE SANTIAGO PARA EL EJÉRCITO DEL NORTE}

El farmacéutico militar compostelano Luis Maiz Eleizegui ${ }^{15}$, que disponía de unos notables conocimientos de farmacia militar ${ }^{16}$,

\section{${ }^{11}$ PEÑA TORREA, F. (1941), p. 106.}

${ }^{12}$ Portugal no se sumó a la postura promovida por Gran Bretaña y Francia de no intervención, por lo que a través de sus fronteras accedieron tropas alemanas y se proporcionó material bélico al bando franquista. Los productos sanitarios introducidos por esta vía fueron bienvenidos, aunque cuantitativamente escasos.

${ }^{13}$ PEÑA TORREA, F. (1941), p. 36.

${ }^{14}$ GÓMEZ RODRÍGUEZ, L. (1989). p. 317.

${ }^{15}$ Luis Maiz Eleizegui (1880 - 1967) estudió la carrera de Farmacia en Santiago, su ciudad natal, y se licenció con premio extraordinario. En 1909 ingresó por oposición en el Cuerpo de Farmacia militar.

${ }^{16}$ En la hoja de servicios de Maiz Eleizegui aparece su trayectoria en la carrera militar en los años previos a la creación del Laboratorio. Desde 1909 pertenecía al cuerpo de Farmacia Militar del Ejército al que accedió, previa oposición, como farmacéutico segundo (teniente). Durante los primeros años de servicio tuvo varios destinos en diferentes hospitales militares -Alicante, Palma de Mallorca, Valladolid, A Coruña, Larache (Tetuán)-y en el Ministerio de la Guerra en Madrid. En 1926 fue destinado al Laboratorio Central de Medicamentos de Madrid, como Farmacéutico Mayor. Sin duda, estos años le sirvieron como aprendizaje del funcionamiento de un centro de sanidad militar que, posteriormente, pondría en marcha en Santiago.

En julio de 1931 se retiró voluntariamente del cuerpo del ejército y así permaneció los casi cinco años que duró la II República. Suponemos que esta baja voluntaria se debía a su desacuerdo con el régimen político instaurado en España desde el 14 de abril de 1931, puesto que cuando 
comprendió enseguida que la falta de centros de producción en la llamada zona nacional, conllevaría una inmediata escasez de medicamentos y productos sanitarios. Con la aprobación del decano, Antonio Eleizegui López y del claustro de profesores de la Facultad de Farmacia de Santiago, cursó una propuesta a la autoridad militar de la plaza, el teniente coronel Francisco Judel Peón, y en poco tiempo se organizó un laboratorio de producción de medicamentos y material de cura en la sede de la Facultad, el Colegio de Fonseca.

La Facultad de Farmacia de Santiago de Compostela tenía su sede en este palacio renacentista del siglo XVI, desde la implantación de la carrera de Farmacia en la Universidad de Santiago en 1857. A las dificultades endémicas del edificio como centro de investigación y docencia, se sumaron las de su adaptación para la producción de medicamentos y de material de cura a mayor escala.

Sin embargo, la dotación material adquirida en los cinco años precedentes, la colocaba en una situación favorable para afrontar el reto planteado. En 1931 se habían reformado las cátedras de Análisis Químico y de Técnica Física, con la adquisición de muebles de trabajo y de almacenaje, acondicionamiento de los laboratorio, abastecimiento de agua corriente, así como nuevos y modernos aparatos para su uso en investigación, lo que permitió su mejor adaptación para los trabajos requeridos por el Ejército.

Como las instalaciones de la Facultad de Farmacia no permitían la colocación y funcionamiento de telares para producir género, fueron intervenidas dos fábricas de tejido de algodón para fabricación de gasas y vendas de la provincia de A Coruña: en Xubia $^{17}$ y en Padrón ${ }^{18}$. En ambas fábricas, siguiendo las directrices

se produjo el llamado Movimiento Nacional en julio de 1936, inmediatamente se personó en la Comandancia Militar de Santiago para coordinar la sección de donativos de víveres. En agosto de ese mismo año ya dirigía el Laboratorio de Farmacia Militar en la Facultad en Fonseca. No deja de ser relevante que a Maiz le fuese concedida en agosto de 1933 la Cruz de la Orden Militar de San Hermenegildo, cuando estaba retirado del Ejército. En: ARCHIVO GENERAL MILITAR DE SEGOVIA. Ejército de Tierra. Cuerpo de Farmacia Militar. Hoja de servicios y de hechos del Subinspector farmacéutico de $1^{\text {a }} \mathrm{D}$. Luis Maiz Eleizegui. Sección 1, Legajo M-188, folio 3.

${ }^{17}$ Esta fábrica textil fue anteriormente la Real Fábrica de Moneda y Cobrería de Jubia (A Coruña), fundada en 1790. En 1876 un particular la compró al Estado y la transformó en fábrica de hilados y tejidos. En 1928 pasó a manos de Dionisio Tejero Pérez, bajo el nombre de Galicia Industrial. En 1982, inmersa en fuerte crisis de deudas y embargos, la empresa fue absorbida por un grupo textil catalán, constituyendo la actual Galicia Textil, S.A. En PITA FERNÁNDEZ, R. L.: A Real Casa da Moeda de Xubia: breve historia e catálogo das súas cuñacións, Santiago de Compostela, Tórculo Edicións, 1996.

${ }^{18}$ En su publicación Una aproximación a los procesos de cambio en la Galicia rural a través del análisis de los municipios de Brión y Padrón (1850-1970), M $\mathrm{M}^{\mathrm{a}}$ Pilar Freire señala que esta fábrica textil era la más importante en la comarca y había sido fundada en 1886 por Ángel Ramos García. Desde 1918 estaban al frente su viuda y sus dos hijos. Fabricaban lienzos de lino y algodón que eran vendidos en España y exportados a Cuba y Brasil. A comienzos de la década de los 30 se instalaron telares mecánicos que funcionaban con energía eléctrica. Los años de la guerra civil fueron, según la autora, los de mayor productividad para la empresa, gracias a la militarización llevada a cabo para abastecer al Laboratorio de Farmacia de la Facultad de Farmacia de Santiago. Entre 1936 y 1940 los telares mecánicos se incrementaron de dos a diecisiete. FREIRE ESPARÍS, M.P.: «Una aproximación a los procesos de cambio en la Galicia rural a través del análisis de los municipios de Brión y Padrón (1850-1970)», Revista Galega de Economía, vol. 16, núm. extraord. (2007). de la obra «Industria textil sanitaria», escrita por farmacéuticos, se varió el hidrofilado de la gasa tras varios ensayos. Esto dio como resultado un material de excelente calidad, muy estimado por el personal sanitario en los hospitales de sangre a los que era enviado.

La primera labor que llevó a cabo el Laboratorio, fue la de reunir e inventariar todos los medicamentos disponibles. Se solicitó a los médicos gallegos la donación de las muestras de medicamentos que las casas farmacéuticas solían enviarles. Así se recoge en el periódico local El Compostelano en fecha de 22 de agosto de 1936:

«En la Facultad de Farmacia, gracias a las facilidades dadas por el decano Sr. Eleizegui con cooperación de los profesores, han quedado hoy establecidas en la sección de material sanitario y medicamentos dos subsecciones: una de inyectables donde se prestarán los de más urgencia y otra de cura aséptica, en la que se elaborarán gasas, compresas, vendas, etc.

En esta sección continúan recibiéndose valiosos donativos de medicamentos y material sanitario, donados por los médicos, farmacéuticos y practicantes de la localidad, a quienes enviamos desde aquí la expresión del mayor agradecimiento en nombre del Ejército».

Las siete secciones en que estaba dividido el Laboratorio eran las siguientes:

Sección I: Especialidades e investigaciones

Sección II: Productos químicos

Sección III: Inyectables

Sección IV: Preparaciones galénicas

Sección V: Cura aséptica y antiséptica

Sección VI: Botiquines de batallón

Sección VII: Vacunas

\section{PLANTILLA DEL LABORATORIO DE FARMACIA MILITAR DE SANTIAGO DE COMPOSTELA}

La plantilla del Laboratorio de Farmacia Militar de Fonseca fue creciendo a lo largo de los tres años de conflicto bélico. Estaba compuesta por miembros de la Facultad de Farmacia, -profesores, alumnos, recién licenciados, etc. -, algún hombre exento de coger las armas y, sobre todo, señoritas voluntarias de las familias más distinguidas de Santiago, por lo común, con algún médico o farmacéutico entre sus miembros.

Así resumía Peña Torrea, a quien unía una relación de amistad con Maiz Eleizegui, los comienzos de este laboratorio y la organización del personal:

«En el mes de agosto de 1936 empezaba a funcionar [...] el Laboratorio químico-farmacéutico de Santiago de Compostela bajo dirección del referido farmacéutico militar y con la entusiasta colaboración del Decano, Catedráticos y alumnos, así como de numerosas señoras y señoritas de la localidad que se prestaban voluntaria y gratuitamente a ello, poniendo todos sus mejores y más bellos pensamientos en los santos ideales de Dios y España y sus caritativos corazones en ese heroico soldado que en peregrinación guerrera combatía y derramaba su sangre por la redención de una Patria, oprimida y vendida al materialismo ateo y judaico».

Marita Poch, que fue una de las primeras en acudir voluntaria al Laboratorio, relata cómo fueron aquellos primeros momentos: 
«Cuando estalló la guerra fuimos al Servicio de España a prestar ayuda. Pero, la verdad, yo ya me cansaba de estar todo el día cosiendo calzoncillos... Entonces nos dijeron que pedian gente para el Laboratorio de Farmacia y alli fuimos voluntarias: Al principio seríamos unas quince chicas, de las que sólo una estaba casada, Rosario Bescansa. Todas teníamos entre 17 y veintipocos años. Después llegaron las del Servicio Social, y aquello fue la invasión de los bárbaros del norte... Todas querían venir al laboratorio, que era mucho más bonito que, por ejemplo, ir a las guarderías. Se estropeó un poco el ambiente, pero también trabajábamos más».

También Concepción Villar ${ }^{19}$, recuerda cómo una verdadera «legión de bata blanca» acudió al Laboratorio para ayudar en la producción de medicamentos y apósitos:

«Pidieron chicas y alli nos presentamos. No hacía falta que fueran farmacéuticas, de hecho, tan sólo Marisa Lema, Pepita Ron y Ramonita Vaamonde estudiaban en la Facultad. Cuando llegamos, salió Eleizegui, el decano y nos dijo: -Pero, ¿qué hacéis aquí? Hala, hala, iros, que aquí no hacéis nada. Luego salió Maiz y le replicó:¿Cómo que no? ¡Pasad, que aquí lo que faltan son manos que nos ayuden! Y asi empezamos. Maiz era encantador, pero Eleizegui era un cascarrabias..., no te puedes dar idea».

En los primeros momentos la colaboración femenina fue espontánea, ningún organismo oficial la coordinó. Santiago era una ciudad pequeña, de alrededor de 25.000 habitantes en 1936, en la que era habitual conocerse. En poco tiempo el boca a boca llevó a las puertas de Fonseca a las muchachas deseosas de prestar su colaboración para auxilio del combatiente, que en muchos casos eran sus propios familiares y amigos. Posteriormente, el Servicio Social se ocupó de las labores de coordinación para la entrada de personal en el Laboratorio, incrementándose de esta manera la plantilla de voluntarios del centro.

El profesorado de la Facultad de Farmacia pasó a trabajar en el Laboratorio de Farmacia Militar con la condición de militares asimilados, según la norma ${ }^{20}$ establecida por la Junta de Defensa Nacional del Gobierno provisional en Burgos y publicada en su Boletín Oficial. La jerarquía académica se mantuvo también a la hora de hacer los nombramientos militares: los catedráticos fueron asimilados con el grado de capitán y los profesores auxiliares y ayudantes como tenientes y alféreces.

Según el libro del centenario de la Facultad escrito por Maiz ${ }^{21}$ posteriormente, el organigrama era el siguiente:

- Dirección: Comandante farmacéutico Luis Maiz Eleizegui.

- Subdirección: Antonio Eleizegui López, decano de la Facultad y capitán asimilado.

- Jefe de la Sección I de Especialidades e Investigación: Ricardo Montequi y Díaz de Plaza, catedrático de Química Inorgánica y capitán asimilado.

- Jefe de la Sección II de Productos químicos:

- Jefe de la Sección III de Inyectables:

\footnotetext{
${ }^{19}$ VILLAR BLANCO, C. (6 de noviembre de 2007). Declaraciones a la autora.

${ }^{20}$ El Decreto número 110 del Boletín Oficial de la Junta de Defensa Nacional de España, de 17 de septiembre de 1936, recogía la asimilación al ejército de los médicos y practicantes que prestasen sus servicios al ejército sublevado en equipos quirúrgicos, hospitales de guerra, líneas avanzadas, puestos de socorro de retaguardia y ambulancias. En $B O E$ de 15 de octubre del mismo año se ampliaba la norma a los farmacéuticos.

${ }^{21}$ MAIZ ELEIZEGUI, L. (1961), p. 72 y 82.
}

- Jefe de la Sección IV de Preparaciones galénicas: Antonio Eleizegui López, decano de la Facultad y capitán asimilado.

- Jefe de la Sección V de Cura aséptica y antiséptica: Eduardo Vilariño de Andrés-Moreno, profesor auxiliar de Farmacia práctica y alférez ${ }^{22}$ asimilado.

- Jefe de Sección VI de Sección VI de Botiquines de batallón: Luis Sánchez Harguindey, médico asimilado a teniente.

- Jefe de la Sección VII de Vacunas: Juan Varela Gil, profesor de la Facultad de Medicina y teniente asimilado.

Los jefes de las secciones II y III fueron, con toda seguridad, los catedráticos Aniceto Charro y Carlos Puente, de Análisis Químico y Farmacia Práctica, respectivamente, ya que en el libro del centenario de la Facultad de Farmacia de Santiago se recoge que ambos fueron jefes de sección del Laboratorio Militar durante la guerra, si bien a la hora de explicar su organización ${ }^{23}$ señala que los jefes de estas dos secciones eran dos catedráticos sin indicar sus nombres. Tanto Charro como Puente no fueron militarizados en su condición de san$\operatorname{cionados}^{24}$ al ser sospechosos de no apoyar el Movimiento Nacional y poseer ideas izquierdistas. Tal vez, a la hora de hacer relación de los jefes de sección dentro del apartado dedicado al Laboratorio en el libro del centenario, Maiz quisiese pasar por alto ese incómodo hecho, puesto que Aniceto Charro continuaba en la Facultad y Carlos Puente había permanecido en su cargo hasta su fallecimiento en 1946.

De los primeros tiempos de funcionamiento se dispone de varias fotografías, en el claustro, los laboratorios y frente a la fachada de Fonseca, en las que aparece el personal del Laboratorio ${ }^{25}$ (Figuras 1-5). La que parece ser una de las primeras es la que se muestra en la página 37 del libro del centenario de la Facultad y en cuyo pie de foto se lee: «Personal con que inició sus trabajos el Laboratorio de Farmacia Militar». En ella contabilizamos un total de 63 personas: 24 hombres y 39 mujeres.

También trabajaron en el Laboratorio otros jóvenes a los que la guerra les había sorprendido lejos de sus hogares y no pudieron regresar hasta que esta terminó. Tal fue el caso de Francisco GarcíaValdecasas $^{26}$, que en aquel tiempo era auxiliar de Fisiología en la Fa-

${ }^{22}$ En los comienzos del Laboratorio, Eduardo Vilariño fue asimilado a farmacéutico $3^{\circ}$ (alférez) tal y como correspondía a su cargo de profesor auxiliar. El 10 de junio de 1937 fue ascendido a farmacéutico $2^{\circ}$ (teniente) mientras trabajaba en el desarrollo de la farmacia móvil modelo Santiago de Compostela. Posteriormente, fue ascendido a farmacéutico $1^{\circ}$ asimilado durante los servicios que prestó en el frente al mando de dicha farmacia móvil durante las campañas de Asturias, Teruel y Levante. ARCHIVO GENERAL MILITAR DE SEGOVIA. Ejército de Tierra, Cuerpo de Farmacia Militar. Hoja de servicios de D. Eduardo Vilariño de Andrés-Moreno. Sección 611, legajo B-388, folios 1-21. ${ }^{23}$ Ibídem, p. 36.

${ }^{24}$ GURRIARÁN RODRÍGUEZ, R. A investigación científica en Galicia (1900-1940): institucións, redes formativas e carreiras académicas. A ruptura da Guerra Civil. Santiago de Compostela, 2004; p. 487. [Tesis doctoral]. Señala el autor que en la sanción que les había sido impuesta se les prohibía acceder a las dependencias de la Facultad, si bien obtuvieron un permiso especial para poder prestar sus servicios en el Laboratorio.

${ }^{25}$ BRASA ARIAS, B. «Siglos XX y XXI», en De Pharmaceutica Scientia. 150 años de la Facultad de farmacia (1857-2007). Santiago de Compostela, 2007, pp. 200-203.

${ }^{26}$ Francisco García-Valdecasas y Santamaría (1910-2005) nació en Córdoba y estudio Medicina en Santiago de Compostela. Terminada la guerra civil, fue nombrado catedrático de Farmacología en la Universidad de Barcelona, de la que fue rector desde 1965 a 1969. 
cultad de Medicina de Madrid y trabajaba en el laboratorio de Juan Negrín, médico y presidente de la II República durante la guerra civil española. Otro colaborador fue Luis Murillo García que, según Concepción Villar «era un chico que estudiaba Medicina y paraba en el España» ${ }^{27}$.

Encontramos un listado de los farmacéuticos que fueron asimilados y trabajaron en el Laboratorio de Farmacia Militar en Santiago en la obra ${ }^{28}$ de Rafael Roldán Guerrero sobre los farmacéuticos militares en la guerra civil:

Directores:

- Antonio Eleizegui López

- Luís Maiz Eleizegui

Oficiales:

- Ramiro Rueda Fernández

- Rafael Álvarez Salgueiro

- Enrique Bermejo Goday

- Jaime González Carreró

- José Lema Trasmonte

- Ricardo Montequi y Díaz de Plaza

- Enrique López Niño

- Enrique Otero Aenlle

- Eugenio Torres Enciso

- José Vilanova Piñeiro

- Eduardo Vilariño de Andrés-Moreno

- Fermín Zelada Varela

Entre las jóvenes voluntarias estaban Ramonita Vaamonde, Rita, Socorro, Carmen y Rosario Harguindey, Luisa Pintos Quirós, Purificación Blanco-Rivero, Lourdes Cigarrán, Marisa Lema Pintos, Maruja Gil Casares, Concepción y Maruja Villar Blanco, Rosario Bescansa, Marita, Concepción y Mercedes Poch, Pepita Ron Noya, Conchita Barreiro, Carmen Maiz, Estela de Harguindey, Mercedes Alsina Gómez-Ulla, Celsa Pérez Moreiras, Mercedes y Lolita Blanco de Pérez Sáenz, etc.

Ramona Vaamonde, era hija del doctor Joaquín Vaamonde Rodríguez, un reputado médico compostelano, considerado pionero de la Radiología en Galicia. En 1930 se había licenciado en Farmacia con premio extraordinario, después de haber obtenido matrícula de honor en todas las asignaturas de la carrera. En 1937, durante la guerra civil y su etapa en el Laboratorio de Farmacia Militar, realizó el examen de enfermera en la Facultad de Medicina obteniendo el título $^{29}$. Continuó su labor investigadora y docente en la Facultad hasta su jubilación.

Estudiantes de Farmacia eran Pepita Ron Noya y Celsa Pérez Moreiras. Marisa Lema Pintos, hija del profesor auxiliar de la Facultad José Lema Trasmonte, se había licenciado en Ciencias en 1935. Durante la guerra, se presentó a los «exámenes patrióticos» y aprobó la carrera en dos cursos condensados, si bien es cierto que tres asignaturas le habían sido convalidadas ${ }^{30}$.

${ }^{27}$ El hotel España, actual hotel Compostela, situado en la plaza de Galicia en la ciudad de Santiago de Compostela, era en aquel entonces lugar de hospedaje de los estudiantes foráneos pertenecientes a familias con alto poder adquisitivo.

${ }^{28}$ ROLDÁN Y GUERRERO, R.: La farmacia y los farmacéuticos militares en la guerra de liberación de España, Madrid, 1953.

${ }^{29}$ AHUS. Fondo universitario. Vida académica. Expedientes personales. Leg. 1487, exp. 15.

${ }^{30}$ AHUS. Fondo universitario. Vida académica. Expedientes personales. Leg. 683, exp. 7.
Entre los apellidos de las voluntarias figuraban los Harguindey, una importante familia de industriales de origen vasco que poseyeron la primera casa con ascensor de Santiago de Compostela, situada en la calle del Doctor Teijeiro. El decano Eleizegui y el catedrático Ricardo Montequi estaban casados con sendas mujeres de esta familia. También las familias vinculadas a los establecimientos farmacéuticos de la ciudad como los Bescansa y los Gómez-Ulla aportaron a alguna de sus miembros como voluntaria del Laboratorio. Rosario Bescansa, la única que estaba casada, era la esposa de Luis Maiz Eleizegui. Los apellidos relacionados con la banca local también contribuyeron a la causa: los Pérez Sáenz y los Poch.

Entre los chicos: Juan Touriño, Alejandro Pérez-Labarta, Francisco Perianes Colombo y Andrés Garabal. ${ }^{31}$

A pesar de la penosa situación debida al contexto de una guerra civil en la que la mayoría de los voluntarios tenían un familiar o amigo, el ambiente de trabajo era bueno, en general. Tratándose de gente joven, siempre había momentos para la diversión y las bromas que, en ocasiones, eran reprendidas por los profesores al mando para que no se despistasen del trabajo.

Estos son algunos de los recuerdos de Marita Poch, una de las primeras voluntarias del Laboratorio. De sus palabras podemos extraer la idea del afán con el que se trabajaba y de la entrega total al Laboratorio.

«Yo trabajé los tres años seguidos, por la mañana desde las nueve hasta la una y luego desde las tres hasta que acabábamos. A veces me iba a buscar mi padre y ya eran más de las diez de la noche [...] Fue una época muy bonita. Estábamos todos tan unidos, yo creo que si no llega a ser por el Laboratorio me habría vuelto loca en la Guerra. Porque era ver marchar a todo el mundo y luego volvían: una cajita, otra cajita... Compañeros que trabajaron con nosotras que luego se marcharon. [...]

Un día estábamos preparándonos para ir al Laboratorio cuando se escuchó en la radio que se acercaba un avión y había peligro de ataque aéreo. Mi padre no nos quería dejar marchar, pero yo le dije que sería cualquier avión que se acercaba por ahi y que no había que preocuparse. Ese día sólo éramos cinco en el laboratorio. Al final del día, Juanito Touriño nos hizo unas condecoraciones con un cartón en las que ponía: Ataque aéreo, premio al valor»

En declaraciones al diario $A B C$, publicadas el 5 de noviembre de 1937, el propio director Maiz Eleizegui daba cuenta del numeroso grupo de voluntarias con que contaba la plantilla del Laboratorio:

«- ¿Cuántas muchachas hay ocupadas en los laboratorios?- preguntamos al señor Maiz.

- Cerca de 150. Entre ellas varias profesoras y alumnas de la Escuela Normal. También algunas alumnas de Farmacia que residian aquí. El resto son señoritas de Santiago, admirables muchachitas animadas por el deseo de ser útiles a su Patria. Puede usted decir que son todas unas colaboradoras excelentes».

\footnotetext{
${ }^{31}$ Lista de personal realizada a través de las identificaciones de las fotografías existentes realizadas por Concepción Villar y Marita Poch. El profesor José Carro también ha realizado una identificación del personal en CARRO OTERO, X. «El Laboratorio de Farmacia Militar en Santiago (1936-1939)» en Materiais para unha Historia da Medicina Galega, Santiago de Compostela, Consellería de Sanidade y a Servicios Sociais, 1998, tomo II, p.151.
} 


\section{VALORACIÓN DEL TRABAJO DE LAS MUJERES EN EL LABORATORIO DE FARMACIA MILITAR DE SANTIAGO: LA PRENSA DE LA ÉPOCA Y LA PROPAGANDA DE POSGUERRA}

La participación de las mujeres voluntarias en el Laboratorio de Farmacia Militar de la Facultad de Santiago de Compostela fue un hecho ampliamente publicitado dentro de la propaganda bélica del bando nacional.

Principalmente en la prensa afín al ejército sublevado, como el periódico local El Compostelano y el diario nacional $A B C$, así como en la obra del general Francisco Peña Torrea, en la que se aprecia la valoración que, en plena posguerra, se hizo de la participación de las mujeres en tareas tan «poco femeninas» como la producción de medicamentos en un laboratorio farmacéutico.

El tono paternalista relacionado con las mujeres que allí trabajaban está presente en la totalidad de publicaciones relacionadas con el Laboratorio, si bien se aprecia una cierta diferencia entre las publicaciones realizadas durante la guerra y las posteriores. Mientras que durante la guerra se hizo hincapié en el trabajo considerándolo competente y cuasi profesional, al finalizar la guerra se trató de enfatizar la abnegación y la sumisión a las órdenes recibidas sin valorar de una manera objetiva la importancia del trabajo realizado.

El 5 de noviembre de 1937 el periódico $A B C$, en su edición sevillana, publicaba en un número especial un reportaje sobre el Laboratorio de Farmacia Militar de Santiago de Compostela. También en Sevilla existía un laboratorio militar de similares características, por lo que la noticia tenía un interés relevante para el diario andaluz.

En este reportaje se señalaba la singularidad del trabajo realizado en él por las mujeres porque, si bien el trabajo femenino era habitual en los talleres de ropa para los soldados del Servicio Social, no lo era tanto el hecho de que las jóvenes fabricasen sueros, vacunas, ampollas inyectables y apósitos estériles. Se mencionaba el apodo de «Legión Blanca» que en Santiago los ciudadanos habían otorgado a las voluntarias que cada día acudían al Pazo de Fonseca ataviadas con batas blancas de laboratorio.

El diario hacía hincapié en la participación femenina como unas trabajadoras más dentro del Laboratorio:

«En todas las secciones las mujeres tienen función importantísima. Ayudan en los trabajos de laboratorio, cuidan de la asepsia de los aparatos, cierran y clasifican ampollas, esterilizan elementos de cura, empaquetan y ordenan... Y todos estos trabajos, que prestan naturalmente con el mayor desinterés, los desempeñan con celo y competencia excepcionales».

Pero el hecho de ser mujeres en la España no republicana durante la guerra, implicaba demostrar una conducta establecida que alejase cualquier idea de que el trabajo realizado era personalmente enriquecedor, y ello queda reflejado en el reportaje:

«Estas muchachas compostelanas son admirables. Trabajan con un fervor casi increíble. Y todo, desde la labor más humilde e insignificante, hasta la más delicada, la ejecutan con el mismo entusiasmo.

- Lo que estamos haciendo- nos dice interrumpiéndonos una linda muchacha que nos escucha-no tiene importancia. Al lado del sacrificio que tienen que realizar los soldados, nuestro trabajo no es nada».

Terminada la guerra el discurso cambió notablemente. Se seguía reconociendo a las mujeres que participaron en el Laboratorio pero desde una óptica diferente. Fiel reflejo son las palabras que el gene- ral Peña Torrea dedicaba en 1941 a las voluntarias del Laboratorio de Farmacia Militar de Santiago.

«Funcionando con este régimen de ayuda económica, generosa y particular, el Laboratorio de Santiago fue extendiendo sus elaboraciones y preparados hasta ocupar todos los locales de la Facultad de Farmacia, contemplándose en sus aulas y Laboratorios, ante mesas, vitrinas o pedaleando en la máquinas de coser gentiles y lindas muchachas, que sin perder la proverbial feminidad de la mujer española, en labor silenciosa y meritoria, sin exhibiciones deslumbradoras, dentro de un soberbio marco de modestia, ciencia y poesía, se realzaban ante Dios y ante los ojos humanos, como bendita simiente de esas madres hispanas, que, tras perder a uno o varios hijos en la Santa Cruzada, aun ofrecían al Caudillo en admirable amalgama de orgullo patriótico, estoicismo y abnegación, los hijos que le quedaban en holocausto de la Civilización Cristiana».

El párrafo es francamente elocuente. Se insiste continuamente en que, a pesar del trabajo, las muchachas seguían siendo femeninas, reafirmando la idea de que ninguna mujer debería considerarse como tal si no estaba dentro del ámbito del hogar y la familia. Representa a las mujeres que allí colaboraban como entes autómatas que apenas levantaban los ojos de su tarea, sin pensar que el trabajo que hacían tenía algo de meritorio. El más alto reconocimiento para una mujer era la pérdida de sus hijos en el combate.

Sin embargo, por las entrevistas con dos de las mujeres que fueron voluntarias durante la guerra en el Laboratorio de Farmacia Militar, sabemos que el ambiente era diferente. Los jefes y compañeros valoraban el trabajo de las chicas que, a fin de cuentas, eran la principal mano de obra. Marita Poch, en ocasiones, se quedó encargada de cerrar la puerta del Laboratorio una vez que todo el mundo se había marchado porque el autoclave aun no había terminado su ciclo de esterilización ${ }^{32}$.

Los profesores que dirigían las secciones del Laboratorio estaban acostumbrados a la presencia de las mujeres en las aulas y los laboratorios de la Facultad, incluso a publicar trabajos científicos con ellas, de manera que no existían motivos para un trato diferente y receloso para con las voluntarias. Pero a la propaganda del nuevo régimen establecido tras la guerra no le importó nada de esto y la Historia se escribió de manera interesada para crear el nuevo marco social en el que las mujeres tenían predeterminado su papel.

\section{FINANCIACIÓN}

El 5 de marzo de 1937 el Laboratorio de Medicamentos de la Facultad de Farmacia de Santiago de Compostela fue declarado oficial $^{33}$, pasando a denominarse Laboratorio de Farmacia Militar de Santiago de Compostela y quedando englobado dentro del Parque Farmacéutico del Ejército del Norte. En esta militarización del centro productor de medicamentos tuvo gran importancia el general Cabanellas, quien visitó ${ }^{34}$ el Laboratorio y gestionó su militarización ${ }^{35}$.

\footnotetext{
${ }^{32}$ POCH Y DÍAZ DE RÁBAGO, M. (20 de diciembre de 2007). Declaraciones a la autora.

${ }^{33}$ MÁIZ ELEIZEGUI, L: «Labor realizada en el primer año por el Laboratorio Militar de Santiago», El Compostelano de 21 de agosto de 1937.

${ }^{34}$ En El Compostelano de 11 de enero de 1937.

${ }^{35}$ En El Compostelano de 23 de mayo de 1938. Se recoge una noticia breve en la que se anuncia que el personal del Laboratorio de Farmacia Militar costeará una misa en la Capilla de la Corticela (Catedral)
} 
Desde el comienzo de su actividad hasta esta fecha, su principal fuente de ingresos fueron las donaciones de los particulares o de las instituciones compostelanas ${ }^{36}$. La prensa local, el periódico $\mathrm{El} \mathrm{Com-}$ postelano, se hizo eco de todos los donativos de particulares -dinero y material diverso- que recibió el Laboratorio. Entre ellos destaca la contribución del Teatro Principal de Santiago, situado en la Rúa Nova, que dedicaba la recaudación de la función de las 19:30 h de todos los viernes a su beneficio (Figura 6).

Después de ser declarado oficial se recibió dinero del Ejército, lo que permitió incrementar su producción. No disponemos de ningún documento ni orden oficial certificando este hecho -la publicación en el Boletín Oficial de los diferentes mandatos y órdenes estaba sujeta a toda clase de irregularidades- pero el propio director del Laboratorio, Maiz Eleizegui, hacía la siguiente afirmación al respecto:

«Desde el $1^{\circ}$ de abril del corriente año fue declarado establecimiento oficial, siendo en la actualidad el centro farmacéutico de producción más importante para el suministro del Ejército del Norte. Con este motivo el aumento en la elaboración ha subido en tal proporción que en la sección de inyectables, por ejemplo, de 15.000 ampollas que se preparaban en el primer mes alcanzó la cifra de 82.000 en el pasado mes de julio [...]».

Por ello, deducimos que se recibieron fondos oficiales que permitieron elevar la producción del Laboratorio.

Sin embargo, también continuaron las donaciones particulares y procedentes de las galas benéficas del Teatro Principal.

\section{LA FARMACIA DE CAMPAÑA MODELO «SANTIAGO DE COMPOSTELA»}

Durante la primavera de 1937, el farmacéutico compostelano y profesor auxiliar de la Facultad de Farmacia, Eduardo Vilariño de Andrés-Moreno, trabajó en el diseño, desarrollo y construcción de una farmacia-automóvil con la que poder dar servicio a varios puntos del frente bélico y a los hospitales de sangre que estaban alejados de los centros de abastecimiento de medicamentos del ejército.

La idea inicial partió del director del Laboratorio de Farmacia Militar, Luís Maiz Eleizegui ${ }^{37}$, y pronto contó con el apoyo del doctor Vilariño, quien realizó unos bocetos de la farmacia-automóvil. En su hoja de servicios ${ }^{38}$ se recoge este hecho:

«...fue encargado por el Jefe de Servicios de la región y previas las instrucciones y datos necesarios de estudiar y planear la construcción de una Farmacia-automóvil, trabajo que realiza rápida y brillantemente siendo aceptados sus planos y construida bajo su

«por el eterno descanso del Excmo. Sr. general Cabanellas, que honró con su visita el Laboratorio gestionando la militarización del mismo». Al día siguiente, en el mismo periódico, se recogió la noticia de la celebración de la misa, a las nueve y media, a la que asistió todo el personal del Laboratorio y que fue presidida por el comandante Militar de la Plaza, Francisco Judel Peón.

${ }^{36}$ PEÑA TORREA, F. (1941), p. 49.

${ }^{37}$ LÓPEZ DE VILARIÑO, J. A.: «La historia de la farmacia militar modelo Santiago de Compostela», El Correo Gallego de 7 de septiembre de 1997.

${ }^{38}$ ARCHIVO GENERAL MILITAR DE SEGOVIA. Ejército de Tierra, Cuerpo de Farmacia Militar. Hoja de servicios de D. Eduardo Vilariño de Andrés-Moreno. Sección 611, legajo B-388, folios 1-21. dirección esta nueva unidad farmacéutica de campaña pidiendo voluntario ser destinado a la misma [...]».

Una vez que el general Aranda, jefe del $8^{\circ}$ Cuerpo del Ejército de Galicia, operativo en la zona de Asturias, mostró su interés y dio el oportuno consentimiento, comenzaron las labores para la realización del proyecto.

El profesor Vilariño era farmacéutico $3^{\circ}$ asimilado al inicio de este proyecto de construcción de la farmacia móvil, tal y como correspondía a su plaza de profesor auxiliar de Farmacia Práctica en la Facultad. Sin embargo, fue ascendido ${ }^{39}$ a farmacéutico $2^{\circ}$ (teniente) mientras trabajaba en el proyecto, lo que hace evidente el buen grado con el que el mando militar acogió su idea de desarrollar una farmacia de campaña.

Se necesitaban fondos para la construcción de la farmacia móvil, de modo que se pensó en organizar una serie de veladas benéficas en diversas ciudades gallegas. Este festival de música y danza estaría producido e interpretado por las jóvenes de la plantilla de voluntarias del Laboratorio de Farmacia militar.

La idea del festival según el relato de algunas de las participantes que hemos podido entrevistar, Concepción Villar y Marita Poch, partió del maestro Benedicto, un músico madrileño al que la guerra había sorprendido en Santiago y que permaneció en la ciudad durante esos años. También colaboró un arquitecto y pintor compostelano, de apellido Baquero, en el montaje del escenario y de los decorados.

El 28 de abril de 1937 se estrenó en el Teatro Principal de Santiago de Compostela el espectáculo, que dada su original y brillante puesta en escena, tenía prevista una asistencia masiva en la ciudad.

El periódico local El Compostelano de 27 de abril de 1937 anunciaba así la función:

Velada en el Principal a beneficio del Laboratorio de Farmacia Militar

Mañana miércoles a las siete y cuarto de la tarde y en el Teatro Principal, tendrá lugar la velada que un grupo de distinguidas señoritas organizan, bajo la dirección artística del maestro don Rafael Benedicto.

He aqui el programa:

$1^{\circ}$. «Ensueño». Música de Schumman. Cuadro de mímica de niños. Niña: Julita García.

$2^{\circ}$. «Cuadro castellano». Música de Benedicto, canciones, recitados, bailes y romances del pueblo.

$3^{\circ}$. «Bailete», que consta de tres partes, A) Massenet vals; bailado por diez distinguidas señoritas. B) Humouresk, Dvorak, tiempo lento y gracioso, bailado por la señorita Marité A. y F. Cid. C) Mazurca Schopin. Por la anterior y las señoritas Marita y Carmela Poch, Miska Remuñán, María del Rosario Leite, Tilita L. Grado, Julita

\footnotetext{
${ }^{39}$ Tenemos noticia de este ascenso a través de la obra del farmacéutico militar Rafael Roldán Guerrero Diccionario Biográfico y Bibliográfico de autores farmacéuticos españoles, en la que se recoge este dato. La orden para tal mérito fue de 10 de julio de 1937, antes de salir con la farmacia-móvil hacia Asturias. Sin embargo, este ascenso no aparece en el BOE de la época, como sí ocurre con el segundo ascenso de teniente a capitán del 12 de enero de 1938. En la publicación de las distintas órdenes en el BOE de la Junta de Burgos en aquellos años eran muy frecuentes esta clase de errores y omisiones, como hemos podido comprobar a lo largo de la investigación para la realización de este trabajo. En ROLDÁN GUERRERO, R. Diccionario Biográfico y Bibliográfico de autores farmacéuticos españoles, Madrid, 1958 1976, vol. 4, pp. 709-710.
} 
García, María Teresa Rassa, Celsita P. Moreira, Julita Cimadevila y Conchita Barreiro; tocadas de atavíos románticos en todo el Bailete. $4^{o}$. «Estampa de antaño». Canciones de Weber, Schubert y Grieg, traducción de Benedicto; por la señora María Carlota de Crespo, acompañada al clave.

$5^{\circ}$. «Danzas noruegas», Grieg. Pareja central, señoritas Tilita L. Grado y Merche Barreiro, bailan aqui las del ballet, con las señoritas Purita F. garrido, Milagritos Alsina Gómez-Ulla, Pilar de la Peña Rofignac, Clarita Sobrino, Pepita Rivera y Lolita Fondo.

Sin duda se trataba de un programa muy al gusto de la época, musicalmente muy rico y que, además, contaba con el atractivo de ver a las jóvenes de las familias distinguidas cantando y bailando ataviadas con hermosos trajes de baile. Una anécdota: para confeccionar las faldas de las danzas noruegas se empleó gasa del laboratorio, que volvió a ser convenientemente reutilizada una vez terminada la representación, como era menester en tiempos de guerra.

El éxito de la función fue tal, que el viernes 1 de mayo volvió a representarse en el Principal. En nota de prensa de El Compostelano, de 2 de mayo de 1937 se recoge:

«...Con un lleno superior, si cabe, al del día de la presentación, la sala animose de un selectísimo público, [...] Es de hacer notar la colaboración de los señores Antonio Gil, Méndez Brandón, Cordero Carrete y Brage por lo que respecta a dirección y no lo es menos, la prestación de todos los elementos de la orquesta y el propietario de la Peluquería Varela, que los dos días de la función colaboró al arreglo de tocador de las señoritas que en la fiesta actuaron».

Es cierto que no se escatimó en medios para estas «Fiestas de Arte». Concepción Villar cuenta cómo se representó el «Cuadro castellano»:

«Carmen Varela hizo de reina Isabel y mi hermana Maruja del rey don Fernando, que llevaba una capa de la casa de Rábago que la tenían como oro en paño porque era una cosa antiquísima. Era azul con estrellas plateadas y nos la dejaron por ser quiénes éramos. Mi madre estaba angustiadísima con la capa: mi hermana subía al escenario y se la ponían, y al bajar se la quitaban enseguida para que no le pasase nada a la capa. Creo que la donaron para un museo en La Puebla. La cama que se utilizó como decorado en la obra era preciosa, con dosel, y fue de casa de las de Varela, del Toral. Todo muy bien presentado, no fue una velada corriente».

También Marita Poch, quien empezó como colaboradora de sastrería y acabó bailando en la función, nos da más detalles:

«Primero había un número de niños: uno vestido de general y los demás desfilando detrás. La protagonista era una niña que dormía y soñaba con todo esto. También había otros más pequeñitos, vestidos de payasitos que daban palmadas y cantaban. La obra de Castilla era estupenda, y los focos los prestaron de los escaparates de las tiendas de Santiago. Las danzas escandinavas eran de unas chicas vestidas con trajes típicos de Noruega de color negro, verde y rojo. ;Lo que tuvimos que lavar luego para que le saliese el tinte, porque era gasa del Laboratorio y tuvimos que reutilizarla! Lo pasamos fantástico ensayando en el casino. Se hicieron funciones en Villagarcía, Vigo. Coruña y Pontevedra. Todas un éxito, conseguimos dinero suficiente para comprar la camioneta».

Se trató pues de un breve paréntesis para el arte y la música en medio del terrible escenario de la guerra. El propósito se cumplió, ya que se pudo financiar la construcción de la farmacia móvil con la recaudación de las diferentes representaciones, y también sirvió de grata experiencia vital a unas jóvenes que estaban día a día trabajan- do en el Laboratorio de Farmacia Militar. Para probar este hecho, no hace falta más que ver la claridad y emoción con la que dos de estas mujeres -nonagenarias en el momento de la entrevista- recuerdan las veladas benéficas del Teatro Principal.

Luís Maiz, en el resumen de la labor realizada por el Laboratorio en su primer año de funcionamiento ${ }^{40}$, señala la importancia que estas funciones tuvieron para la compra del chasis sobre el que se construyó la farmacia móvil:

«Finalmente, como nota original y curiosa, al mismo tiempo que de excelentes resultados económicos, ha sido la idea de distinguidas señoritas, que a él (Laboratorio) concurren, de formar una agrupación artística que, bajo la excelente dirección de un afamado maestro y con la eficaz colaboración de un arquitecto notable escenógrafo, celebraron festivales artísticos a beneficio del Laboratorio en varias poblaciones gallegas. Con lo recaudado en estas fiestas de arte, adquirió el Laboratorio un chasis de automóvil Chevrolet y [...] se construyó en la fábrica de Chavín (Viveiro) una Farmacia de Campaña, dotada de todos los elementos y que uno de estos días saldrá para el frente de Asturias».

La documentación relativa a esta farmacia móvil es realmente escasa en la actualidad. Se cuenta con dos fotografías, interior y exterior, de la farmacia móvil publicadas en el libro del centenario de la Facultad (Figuras 3 y 7). Se conoce también el itinerario que realizó con bastante precisión y la plantilla con la que contó en estos viajes, pero no han llegado hasta nuestros días los planos originales de las tres farmacias móviles que se fabricaron bajo la dirección del profesor Vilariño: dos en Viveiro (Lugo) y una en Zaragoza.

El 24 de agosto de 1937, Eduardo Vilariño envió a la superioridad una memoria recogiendo la información relativa a la fabricación de la farmacia móvil original, y en 1938, otra dirigida al ministro del Ejército haciendo donación del proyecto al Estado Español ${ }^{41}$.

El chasis, de gran capacidad, aproximadamente unos 9 metros de longitud, estaba en sus dos terceras partes dedicado al almacenaje de medicamentos con cajoneras bien distribuidas y organizadas.

Aunque no podemos precisar la totalidad de su dotación material exacta, podemos llevar a cabo una probable aproximación debido a que la primera de las farmacias móviles, la que se proyectó en Santiago de Compostela se basó en un modelo desarrollado por el farmacéutico militar Rafael Roldán Guerrero ${ }^{42}$ en 1935. Este modelo constaba de un equipo de dispensación y otro de análisis. El equipo de dispensación ${ }^{43}$ estaba dotado con cinco cajas para frascos de medicamentos, dos para utensilios voluminosos, cinco para inyectables y dos para medicamentos en latas y bidones. Los equipos de análisis se componían de una caja con ampollas de antígenos y reactivos y material de laboratorio, otra con material de laboratorio heterogéneo, otra con material de laboratorio frágil de vidrio y

${ }^{40}$ MÁIZ ELEIZEGUI, L: «Labor realizada en el primer año por el Laboratorio Militar de Santiago», El Compostelano de 21 de agosto de 1937.

${ }^{41}$ Estas dos memorias aparecen citadas en GUERRERO ROLDÁN, R. (1958-1976), p. 710. No ha sido posible localizarlas en ningún archivo militar del Ejército de España ni en el actual Ministerio de Defensa. Suponemos que ninguna de las dos han llegado hasta nuestros días o, si lo han hecho, no se encuentran catalogadas.

${ }^{42}$ Rafael Roldán Guerrero publicó desde finales de la década de 1920 varios trabajos referentes al servicio de farmacia militar durante las campañas bélicas aprovechando su experiencia en la guerra del Rif (1910-1926).

${ }^{43}$ GÓMEZ RODRÍGUEZ, L. (1989), p.359. 
porcelana y una cuarta con microscopio, granatario de precisión y material diverso.

Estas cajas iban colocadas en el interior del chasis de manera que ocupasen el menor espacio posible pero que a su vez permitiesen un acceso fácil a los medicamentos. Al llegar al destino del suministro, se desmontaban y organizaban de manera que los medicamentos y el material de cura quedasen ordenados y fácilmente dispuestos para su uso.

La farmacia móvil modelo Santiago de Compostela realizó un itinerario por los puntos estratégicos de batalla durante la guerra civil, dando cobertura sanitaria a los soldados y a la población civil. También eran frecuentes los análisis de aguas al llegar a las poblaciones que iban siendo anexionadas. El primer viaje que realizó la farmacia móvil fue entre finales del mes de agosto y principios de noviembre de 1937, en el frente astur-leonés. El segundo desplazamiento se realizaría durante la campaña de Aragón, en las extremas condiciones climatológicas que presentó el duro invierno de 1937 1938. Allí permaneció hasta finales de febrero de 1938, tras las decisivas batallas de Teruel y Alfambra. Por último, realizó servicio de provisión de medicamentos y material sanitario en la campaña de Levante, que se extendió a lo largo del último año de guerra: de abril de 1938 a abril de 1939.

Terminado su servicio bélico, la farmacia móvil «Santiago de Compostela» se integró en la farmacia del Hospital Militar de Pontevedra ${ }^{44}$.

\section{PRODUCCIÓN E INVESTIGACIÓN DEL LABORATORIO DE FARMACIA MILITAR DE SANTIAGO ${ }^{45}$}

Las noticias respecto a los datos de producción del Laboratorio de Farmacia militar de la Facultad de Farmacia de Santiago están recogidas de la obra acerca del funcionamiento de la Farmacia militar durante la guerra civil española del general Francisco Peña Torrea $^{46}$. Podemos considerar este libro casi como un documento oficial, puesto que ninguna de las memorias que en él se citan y que desde el Laboratorio se enviaron a la correspondiente superioridad, dando cuenta del rendimiento del mismo, han llegado hasta nuestros días. Por ello, podemos hacernos una idea del trabajo llevado a cabo en los casi tres años de funcionamiento del Laboratorio a través de los datos publicados por Peña.

\footnotetext{
${ }^{44}$ ARCHIVO GENERAL MILITAR DE SEGOVIA. Ejército de Tierra, Cuerpo de Farmacia Militar. Hoja de servicios de D. Eduardo Vilariño de Andrés-Moreno. Sección 611, legajo B-388, folios 1-21.

${ }^{45}$ Como fuente para el conocimiento de la actividad farmacológica y los usos cínicos de los diferentes productos hemos consultado las siguientes obras: Formulario español de Farmacia Militar, 1948. Editado por el Laboratorio y Parque Central de Farmacia Militar, Madrid; RODRIGUEZ NOZAL, R. y GONZÁLEZ BUENO, A. Entre el arte y la técnica. Los orígenes de la fabricación industrial del medicamento. Madrid, 2005; ARROYO Y CARDOSO, E. Vademecum farmacológico o Manual práctico de las propiedades terapéuticas: incompatibilidades y posología de los medicamentos más usados en la práctica médica. Santiago de Compostela, 1932; ASTIER, P. Formulario Astier: vademecum del médico práctico: terapeútica general, tratamiento de las afecciones medicales quirúrgicas y especiales, farmacología, y regímenes y diagnósticos de laboratorio. París, 1928; Pharmakoteka: base de datos de medicamentos antiguos de la Universidad de Barcelona, disponible en http://www.ub.edu/crai/pharmakoteka/index.php

${ }^{46}$ PEÑA TORREA, F. (1941), p.117-118.
}

De él, dice el autor en sus páginas que «desarrolló durante la guerra de la liberación española una brillantísima y delicada labor, en la cual es más de apreciar y valorar la calidad de la misma que su cantidad $\rangle^{47}$. Es cierto que la producción del Laboratorio compostelano no fue mayor que la de otros laboratorios militares de la época.

Sin embargo se destaca en la obra de Peña Torrea la labor de investigación científica realizada en la Facultad, con la que se resolvieron varios problemas relacionados con la producción de material y medicamentos:

«[...] estudiando y resolviendo intrincados problemas de química analítica metalúrgica, además de los que presentaban la preparación y obtención de ciertos medicamentos nuevos para la industria nacional, importados siempre de otros países y que, en las circunstancias imperantes, agravadas por la escasez de divisas, obligaban a obtenerlos [...]».

Hemos clasificado la producción del Laboratorio en vacunas, apósitos y los medicamentos según su acción terapéutica. Viendo este listado de productos farmacéuticos, tenemos una clara referencia de las necesidades sanitarias que una guerra causaba entre las filas de los ejércitos: heridas por arma de fuego, enfermedades venéreas, tuberculosis, etc.

- VACUNAS

Antitetánica

Antitífica

Antivariólica

- MATERIAL DE CURA

Compresas estériles de gasa en caja metálica

Esparadrapo

Paquete de cura individual de manganito de plata:

Vendas de gasa

Vendas de tórax y abdominales, vendas en T.

El paquete de cura individual fue lo primero en lo que comenzaron a trabajar en el Laboratorio según las declaraciones de una de las entrevistadas Marita Poch:

«Al principio empezamos en la sección del paquete individual, que era un paquetito que llevaba el soldado, con una gasita impregnada de una sustancia marrón para la hemorragia, esparadrapo, una compresa y un poco de algodón. No teníamos de nada al principio, ni había algodón $[\ldots]\rangle^{48}$.

La sustancia marrón a la que se refiere era manganito de plata coloidal, un compuesto antiséptico y cicatrizante, preparado en el Laboratorio y que constituyó uno de sus mayores éxitos en cuanto a la investigación galénica. La correcta impregnación se realizaba precipitando el manganito de plata sobre la gasa hidrófila, para lo cual se hacía pasar la gasa por dos sendos baños de sal de manganeso y de plata. La concentración final era aproximadamente del $1 \%$. También recuerda Marita el cuidado que ponían en enrollar correctamente la venda, a fin de que ocupase el menor espacio posible, labor para la que, según ella, eran precisas las manos finas de una joven. El paquete iba correctamente impermeabilizado con pergamino y tela recauchutada.

\footnotetext{
$\overline{{ }^{47} \text { Ibídem, p.113. }}$

${ }^{48}$ POCH Y DÍAZ DE RÁBAGO, M. (20 de diciembre de 2007). Declaraciones a la autora.
} 
Según señala Peña Torrea ${ }^{49}$, el principal centro fabricante del paquete de cura individual era el Parque Farmacéutico de Valladolid, el cuál utilizaba la gasa que provenía del Laboratorio de Santiago. En la Facultad de Fonseca se prepararon también paquetes de cura, pero en menor escala. De paquete de cura individual con compresas de manganito de plata se fabricaron 345.260 unidades.

\section{- ANTISEPTICOS Y ANALGÉSICOS TÓPICOS Ambrina \\ Pasta Lassar \\ Pomada de cloramina \\ Pomada de manganito de plata en tubos \\ Pomada de salicilato y mentol \\ Vaselina estéril}

Las pomadas preparadas en la sección de Preparaciones Galénicas eran fundamentalmente antisépticos tópicos con una acción oclusiva sobre la piel o las heridas, al incorporar como excipientes elementos de naturaleza grasa como ceras, vaselina filante o aceites.

\section{- ANTIÁCIDOS Y ANTIDIARRÉICOS Ampollas de bismuto coloidal ${ }^{50}$ Subnitrato de bismuto}

\section{- ANTITUBERCULOSOS}

Cinamato de bencilo o éter bencilcinámico

Gluconato cálcico electrolítico y de fermentación ${ }^{51}$

Iodometilato de urotropina

Lactobionato cálcico

Durante la guerra civil española el tratamiento más habitual para combatir la tuberculosis pulmonar era la calcioterapia ${ }^{52}$, de ahí la importancia de los preparados a base de calcio realizados en el Laboratorio de Farmacia Militar. Se administraba principalmente por vía intravenosa, resultando una terapia dolorosa y con efectos secundarios indeseables como necrosis y quemaduras en los tejidos adyacentes. Hasta los años 50 del siglo XX no se comenzó a utilizar la estreptomicina y la isoniacida para tratar la enfermedad.

\section{- ANTIPIRÉTICOS}

Ampollas de cloruro de quinina

Ampollas de salicilato sódico

\footnotetext{
${ }^{49}$ PEÑA TORREA, F. (1941), p.114.

${ }^{50}$ A propósito de las ampollas de extracto de opio, Marita Poch recordaba cómo era frecuente la desaparición de varias unidades del Laboratorio: «La morfina desaparecía siempre, no era ninguno del laboratorio, pero alguien sería, digo yo. Si robaban el gluconato no importaba, porque era en bien de la humanidad, pero la morfina que desaparecía no sería para cosa buena». En POCH Y DÍAZ DE RÁBAGO, M. (20 de diciembre de 2007). Declaraciones a la autora.

${ }^{51}$ Peña Torrea calificó estos inyectables fabricados por el Laboratorio de Santiago como «estables e indoloros». Se creía que el calcio, en contacto con el agua presente en los tejidos pulmonares, formaba hidróxido de calcio que actuaba como un cáustico y antiséptico. Se fabricaron 350.387 ampollas de gluconato de calcio para el tratamiento de la tuberculosis.

PEÑA TORREA, F. (1941), p. 115.

${ }^{52}$ BÁGUENA CERVELLERA, M.J. La tuberculosis y su historia. Barcelona: Fundación Uriach, 1992; p. 101.
}

- ANTIANÉMICOS Y TÓNICOS RECONSTITUYENTES Ampollas de Canfocal Sulfato de manganeso

\section{- ANTIESPASMÓDICOS Cilotropina}

- VASOPRESORES-BRONCODILATADORES Ampollas de efedrina

- ANTISÉPTICOS URINARIOS

Iodobismutato de quinina soluble e insoluble ${ }^{53}$

Urotropina

Iodometilato de urotropina

Ampollas de Fagoseptina (análogo de la Septicemina) ${ }^{54}$

- ANTIINFECCIOSOS GENERALES

Ampollas de Septoiodo ${ }^{55}$.

\section{- ANTISÉPTICOS DE USO TÓPICO \\ Manganito de plata \\ Subgalato de bismuto \\ Ampollas de tripaflavina ${ }^{56}$ :}

\begin{abstract}
${ }^{53}$ En 1928, el profesor Montequi, jefe de la Sección I del Laboratorio de Farmacia Militar, había publicado en la Revista de Farmacia un trabajo original acerca de la preparación del iodobismutato de quinina como tratamiento de la sífilis. En él, se trataba de perfeccionar el método de preparación del producto que había sido encargado al laboratorio por una oficina de farmacia. El autor habla de un «laboratorio modesto» y de lo difícil que resultaba, a la hora de trabajar, manejar volúmenes de más de 20 litros de agua como así requería la preparación de dicho producto. De este modo, se concentraron los reactivos para llegar a unos volúmenes más manejables dentro del laboratorio. Este trabajo de investigación previo realizada en la Facultad de Farmacia de Santiago permitió un mejor conocimiento de dicho compuesto a la hora de producir el iodobismutato de quinina durante la guerra civil. En MONTEQUI Y DÍAZ DE PLA$Z A, R$. «Preparación del iodobismutato de quinina para uso farmacéutico», Revista de Farmacia, 4, abril de 1928, pp. 121-128.
\end{abstract}

${ }^{54}$ la septicemina era un antiséptico fabricado e importado desde Francia. A propósito de la septicemina francesa, señalaba Peña Torrea que en el Laboratorio de Santiago «una vez descubierta su composición, procediose a prepararla, obteniendo primero para ello el yoduro de metilo y luego el yodometilato de urotropina, consiguiéndose de este modo llegar a las soluciones inyectables que, con el nombre de $\mathbf{F a}$ goseptina empezó, desde entonces, a administrarse en los Hospitales Militares nacionales». Se trataba de un medicamento indicado para las infecciones del tracto urinario, que ante la imposibilidad de obtenerlo directamente del laboratorio francés fabricante, se analizó, se copió y se rebautizó en el Laboratorio de Fonseca, con el nombre de «fagoseptina». En: PEÑA TORREA, F. (1941), p. 114.

${ }^{55}$ El Septoyodo ${ }^{\circledR}$ era una especialidad comercializada en España por el laboratorio S.A. La Industria Hispano-Alemana de Productos Químicos desde el año 1925.

${ }^{56}$ Los profesores Raúl Nozal y Antonio González señalan que ya desde principios del siglo XX las ampollas inyectables contaban con numerosa literatura científica en España. Desde que S. Limousin las desarrollase en 1886, su interés para la terapéutica fue creciendo, gracias sobre todo a varios trabajos sobre el tema realizados por farmacéuticos militares. Señalan los autores que «en todos estos trabajos, así como en la abundante bibliografía aparecida en la prensa profesional durante todo el primer tercio del siglo XX, se constata un amplio conocimiento de las técnicas de elaboración de inyectables, principalmente por parte de algunos colectivos profesionales, como el de la Farmacia militar, 


\section{- ANTITÓXICOS}

Óxido magnésico

Cilotropina

\section{- ANALGÉSICOS Y NARCÓTICOS Éter sulfúrico}

Ampollas de extracto total de opio (análogo al Pantopón)

\section{- CARDIOTÓNICOS}

Ampollas de sulfato de esparteína

\section{- MISCELÁNEA}

Valerianato de amilo

Cloruro cálcico cristalizado ${ }^{57}$ :

Permanganato de plata $^{58}$

Sulfato bárico para radiografía

En el resumen ${ }^{59}$ del primer año de funcionamiento del Laboratorio su director, Luís Maiz Eleizegui, apuntaba los siguientes datos:

«A principios de septiembre ${ }^{60}$ pudo ya hacerse el primer envio de medicamentos y apósitos de diferentes clases a la Farmacia Militar del $8^{\circ}$ Cuerpo de Ejército y seguidamente a los Hospitales Militares de Zaragoza, Valladolid, Burgos, Sigüenza, Zamora, Ceuta, Tetuán, etc. además de atender a las demandas que hacian los de Guitiriz, Cuntis, Santiago y otros. Preparamos inyectables de todas clases, elementos de cura aséptica (compresas, diversos vendajes y paquetes de cura individual), botiquines de campaña, bolsas de campaña que se remitieron a los mencionados centros sanitarios y a gran número de Unidades del Ejército. [...] el aumento en la elaboración ha subido en tal proporción que en la Sección de Inyectables, por ejemplo, de 15.000 ampollas que se preparaban en el primer mes, alcanzó la cifra de 82.000 en el pasado mes de julio. En la de preparaciones galénicas se elaboran actualmente 8 a 10.000 tubos de pomadas antisépticas mensualmente. El número de vendas elaborado durante el año rebasó la cifra de 80.000, 15.000 el de las curas individuales y 8.000 las cajas de compresas esterilizadas. [...] Otra sección que se vio materialmente agobiada de pedidos fue la de Sueros y Vacunas que envió durante el año 20.000 dosis de vacuna antitífica y otras tantas de antivariólica».

Se señalaba asimismo en el artículo, que hasta el momento, era el único laboratorio que fabricaba «copias» de medicamentos franceses imposibles de obtener tras el estallido de la guerra, tales como Pantopon, Septicemina, Septoiodo, Bismuto coloide, etc.

Un año después, desde el mismo diario, aunque esta vez el artículo no iba firmado por Maiz Eleizegui, se hacía balance del segundo año de funcionamiento del Laboratorio de Farmacia Militar de Santiago ${ }^{61}$ :

especialmente familiarizado con este tipo de preparados». En NOZAL RODRÍGUEZ, R. y GONZÁLEZ BUENO, A. (2005), pp. 280-281.

${ }^{57}$ en el Laboratorio se empleaba con un uso industrial, esto es, para desinfección y blanqueo de las gasas de algodón que se recuperaban. ${ }^{58}$ se utilizaba en los filtros de las máscaras antigás.

${ }^{59}$ MÁIZ ELEIZEGUI, L.: «Labor realizada en el primer año por el Laboratorio Militar de Santiago», El Compostelano de 21 de agosto de 1937.

${ }^{60}$ Se refiere a septiembre de 1936. El Laboratorio había sido inaugurado el 20 de agosto, por lo que los primeros envíos se realizaron a las pocas semanas de comenzar a funcionar.

${ }^{61}$ Laboratorio de Farmacia Militar de Santiago. Segundo aniversario de su fundación. El Compostelano, 20 de agosto de 1938.
«Cúmplense en estos días los dos años de la inauguración de este centro establecido en la Facultad de Farmacia. Desde $1^{\circ}$ de enero del año actual está agregado a la Farmacia Parque de la $8^{a}$ Región militar, suministrando medicamentos y diversos elementos de cura a todos los Hospitales y Farmacias Militares de la región mencionada y además el Parque del Ejército del Centro (Valladolid) y algunos extraordinarios a las Farmacias del Cuerpo de Ejército de Galicia (Castellón).

Su actividad en este $2^{\circ}$ año acrecentose extraordinariamente, especialmente en las secciones de inyectables y de cura aséptica y antiséptica. En la primera alcanzó lo elaborado la elevada cifra de 700.000 ampollas de medicamentos inyectables, figurando en este número unas cuarenta clases de diferentes preparados del año anterior (pantopón, gluconato cálcico, colesterino, neumoquín, etc.) y algunas fórmulas nuevas como las de Disolquin (análogo al Selvachis), la Calcio-quinina (sustitutivo del Selvechis cálcico), y otros. El medicamento que acusó más movimiento fue el Glucomonio cálcico, del que se prepararon 110.000 ampollas inyectables.

En la Sección de cura antiséptica y aséptica una nueva preparación antiséptica lograda después de originales investigaciones, sirvió de base para la elaboración de 100000 compresas de la misma proporción, utilizadas en los Hospitales de la Región y en varios del frente. En esta misma Sección preparamos diez mil cajas de compresas de Gasa esterilizada.

La Sección de Sueros y Vacunas aumentó sus preparados con el Suero antitetánico, de comprobada eficacia, elaborándose además 10.000 dosis de Vacuna antitifica y 25000 de la antivariolosa.

La de Material Sanitario de Campaña viose favorecida por algunos donativos de importancia, entre ellos por uno muy reciente de 20 Botiquines de Campaña modelo Santiago de Compostela que han sido enviados al Cuerpo del Ejército de Galicia que opera en Levante. Con este número se alcanzó la cifra de los 200 botiquines, remitidos a las diferentes unidades del Ejército.

Para toda la labor realizada contó este Laboratorio, además de ilustres Profesores, que con sus pacientes investigaciones elevaron el número de las preparaciones obtenidas, elaborando nuevas y originales fórmulas, con un nutrido cuerpo técnico de soldados practicantes y con el elemento femenino valioso y abnegado cooperador de esta patriótica obra. Como es sabido, la Sección femenina de este centro fue la primera organización de esta naturaleza en los Laboratorios de la España Nacional. Este puesto de honor en la técnica labor social que se está realizando en la retaguardia que le corresponde de derecho a las señoras y señoritas que desde el primer día y espontáneamente prestaron su decidido concurso al Laboratorio de Farmacia Militar, supieron sostenerlo durante el $2^{\circ}$ año de su actuación, prodigando su abnegación y cariño en pro del soldado herido y enfermo con el mismo entusiasmo que el primer año.

Aunque por haberse encuadrado dicha sección, por recientes disposiciones, en la magna organización del Servicio Social, ha experimentado valiosa ayuda, esperamos sin embargo que continúe la eficaz colaboración voluntaria aludida, pues las exigencias Sanitarias de nuestro Glorioso Ejército siguen siendo apremiantes y necesitan el concurso de todos.

¡Viva España! ;Viva Franco! ;Arriba España!

Además de su labor en el ámbito sanitario, el general Peña Torrea destaca en su libro la importante tarea que desde la Fa- 
cultad de Farmacia de Santiago se realizó en lo que respecta al asesoramiento en cuestiones de química para la industria militar en las diferentes ramas del ejército: Jefatura del Aire, Legión Cóndor, Servicio de Guerra Química, Artillería, etc. ${ }^{62}$. Estos trabajos técnicos y analíticos se recogieron en 367 informes que se incluían en la «Memoria Oficial» que el Laboratorio de Farmacia Militar de Santiago remitió a la Superioridad una vez cesada su actividad. Aunque los informes no parecen haber llegado hasta la actualidad, algunos aspectos de los trabajados son recogidos por Peña Torrea:

Segmentos, pistones y cojinetes de bielas.

Metales antifricción.

Aluminio de émbolos de motores.

Líquidos para frenos.

Aceites de amortiguador.

Aleación de cárter.

Cuproníqueles de piezas de aviación.

Bujías, electrodos y porcelanas.

Casquillos de pie de biela.

Aceros de diversos orígenes.

Piritas.

Gasolina de aviación y de automóvil.

Aislantes de bujías.

Remaches usados en aviación.

Generador de espuma.

Válvulas de admisión y escape.

Fundiciones especiales.

Clorato potásico.

Ácido sulfúrico para bombas incendiarias.

Si comparamos la producción de medicamentos y apósitos del Laboratorio de Farmacia Militar de Santiago con otros que funcionaron durante la guerra como los de Burgos, Sevilla, Granada o Valladolid, efectivamente la producción es cuantitativamente muy inferior.

Para ilustrar estos datos, podemos observar las (Figuras 8-10) en las que se compara la producción de aquellos productos comunes a todos los laboratorios de farmacia militar: las ampollas inyectables y el material de cura (vengas de gasa y paquetes de cura individual).

En el Parque Farmacéutico del Ejército del Centro, situado en Valladolid, se prepararon casi 6 millones de ampollas inyectables, más de 69 millones y medio de comprimidos (aspirina, clorato potásico, piramidón, urotropina, láudano, etc.), 678.192 tubos de pomadas, tres toneladas de granulados, gasas, paquetes de cura, etc. Este laboratorio fue el de mayor producción durante la guerra ya que disponía de las mejores instalaciones.

El Parque Farmacéutico del Ejército del Norte se creó en Burgos a mediados de 1937, de manera que se desdoblase el Parque Farmacéutico de Valladolid. De él pasó a depender el Laboratorio de Santiago. Los datos de este laboratorio recogidos en la memoria de Peña Torrea apuntan una producción de más de tres toneladas de distintos tipos de aguas destiladas, 1.345 kilogramos de extractos fluidos de veintinueve clases, 2.768 de granulados, veintidós tipos de comprimidos (anticatarrales, antidiarreico, antirreumáticos, laxantes) en cantidad de casi 98 toneladas, más de 6 millones de ampollas

62 PEÑA TORREA, F. (1941), p. 116-117. inyectables, casi un millón de tubos de pomada de veinticuatro tipos diferentes y material de cura.

En Sevilla, en el Parque Farmacéutico del Sur, se estableció un taller de soplado y estirado de vidrio para fabricación de ampollas, de las que se obtuvieron más de 8 millones de unidades. Fueron preparados 42 millones y medio de comprimidos, casi 4 millones y medio de inyectables, setenta y dos fórmulas distintas, treinta y dos clases de pomadas en número de más de medio millón de unidades, 4.354 kilogramos de granulados, 1.687 de extractos, material de cura, etc.

En el laboratorio de la Facultad de Granada ${ }^{63}$, filial del anterior, se obtuvieron noventa y cuatro productos diferentes, algunos de ellos en cantidad de varias toneladas como es el caso del sulfato magnésico (45 toneladas) o el cloruro cálcico desecado (17 toneladas). De este laboratorio, cabe destacar su producción de sales de plata, obtenidas a partir de las donaciones de objetos de plata que realizaron los granadinos. Se recogieron 260 kilogramos de plata de los que se obtuvieron 340 de sales argénticas ${ }^{64}$. La producción es notablemente mayor que la obtenida en el laboratorio de Santiago, si bien se trataba de una Facultad mayor y, probablemente, con una mayor dotación de personal.

En el transcurso de la guerra, y cuando el foco de batalla se desplazó hacia Aragón, Cataluña y Levante, comenzó a producir el parque farmacéutico del V Cuerpo del Ejército, establecido en Zaragoza. Se fabricaron más de tres millones y medio de ampollas inyectables, casi once millones de comprimidos, casi trescientos mil tubos de pomadas, más de trece toneladas de alcoholatos, casi cincuenta toneladas y media de diversas aguas destiladas, material de cura, etc.

\section{CONCLUSIONES}

El Laboratorio de Farmacia Militar de la Facultad de Santiago fue un centro de producción de medicamentos para el ejército franquista durante la guerra civil española (1936-1939). Entre su plantilla se encontraban algunos profesores y alumnos de la Facultad, pero la mayor parte de la mano de obra estaba constituida por jóvenes voluntarias. La labor realizada por este Laboratorio, si bien no fue extensa cuantitativamente, si resultó muy importante por la calidad de sus preparados, así como por la investigación realizada en sus laboratorios para tratar de obtener copias de medicamentos extranjeros.

El papel de las mujeres en el Laboratorio de Farmacia Militar de Santiago fue muy relevante, puesto que trabajaron con dedicación y precisión a las órdenes del mando militar. La mayoría de ellas no tenía conocimientos previos en preparación de medicamentos y apósitos, sin embargo pronto demostraron una destreza y perfección que mereció el reconocimiento de las autoridades. A pesar de ello, una vez terminada la contienda, su trabajo quedó un poco en el ol-

${ }_{63}^{63}$ PEÑA TORREA, F. (1941), p. 108-110.

${ }^{64}$ Con estas sales se preparó principalmente argirol, un antiséptico tópico en solución formado por un complejo plata-proteína. En España se comercializaba el Argyrol de Barnes, creado en 1902 por el doctor Albert Coombs. Barnes de Pennsylvania (1872-1952) y el científico alemán Hermann Hille. Fue muy importante su uso en el tratamiento de enfermedades venéreas, como la sífilis. 
vido. Se tardaría décadas en admitir que su trabajo fue tan válido e importante como el de sus compañeros masculinos.

Una de aquellas mujeres, Ramona Vaamonde, recién licenciada en Farmacia unos años antes de que estallase la guerra, permaneció toda su vida en la Facultad de Farmacia de Santiago de Compostela como profesora de Microbiología.

Las mujeres se incorporaron por primera vez a las Academias Militares españolas en el año 1988. Oficialmente forman parte en del Ejército desde hace escasos veinte años. Sin embargo, su participación dentro de las campañas militares durante la guerra civil española fue activa y directa, tal y como aconteció en el Laboratorio de Farmacia Militar de la Facultad de Santiago de Compostela.

\section{BIBLIOGRAFÍA}

1. ANÓNIMO. Formulario español de Farmacia Militar, Laboratorio y Parque Central de Farmacia Militar, Madrid, 1948.

2. ANÓNIMO. Historia de la enseñanza de farmacia en Santiago: cien años de vida de la Facultad: 1857-1957, Santiago de Compostela, Imprenta Paredes, 1961.

3. ARROYO Y CARDOSO, E. Vademecum farmacológico o Manual práctico de las propiedades terapéuticas: incompatibilidades y posología de los medicamentos más usados en la práctica médica. Santiago de Compostela, 1932.

4. ASTIER, P. Formulario Astier: vademecum del médico práctico: terapeútica general, tratamiento de las afecciones medicales quirúrgicas y especiales, farmacología, y regímenes y diagnósticos de laboratorio, París, 1928.

5. BÁGUENA CERVELLERA, M.J. La tuberculosis y su historia. Barcelona: Fundación Uriach, 1992

6. BRASA ARIAS, B. «Siglos XX y XXI», en De Pharmaceutica Scientia. 150 años de la Facultad de farmacia (1857-2007). Santiago de Compostela, 2007, pp. 157-255.

7. CARRO OTERO, X.: Materiais para unha Historia da Medicina Galega, Santiago de Compostela, Consellería de Sanidade y Servicios Sociais, 1998, tomo II

8. DAVID, J. \& BURKITT, D.: «Burkitt's Lymphoma: Remissions Following Seemingly Non-specific Therapy». British Medical Journal, 4, 1968, pp. 288-291.

9. FOLCH JOUS, G.: Historia de la Farmacia. Gráficas Alonso. Madrid, 1972

10. FREIRE ESPARÍS, M.P.: «Una aproximación a los procesos de cambio en la Galicia rural a través del análisis de los municipios de Brión y Padrón (1850-1970)», Revista Galega de Economía, vol. 16, núm. extraord. (2007).

11. GÓMEZ RODRÍGUEZ, L.: La evolución del servicio farmacéutico militar español en el siglo XX, Madrid, 1989. Tesis doctoral.

12. GURRIARÁN RODRÍGUEZ, R.: A investigación científica en Galicia (19001940): institucións, redes formativas e carreiras académicas. A ruptura da Guerra Civil. Santiago de Compostela, 2004. Tesis doctoral.

13. LÓPEZ DE VILARIÑO, J. A.: «La historia de la farmacia militar modelo Santiago de Compostela», El Correo Gallego de 7 de septiembre de 1997.

14. MAIZ ELEIZEGUI, L. «Labor realizada en el primer año por el Laboratorio Militar de Santiago», El Compostelano de 21 de agosto de 1937.

15. MONTEQUIY DÍAZ DE PLAZA, R. «Preparación del iodobismutato de quinina para uso farmacéutico», Revista de Farmacia, 4, abril de 1928, pp. 121-128.

16. NICOLAOU, K.C. y MONTAGNON, T. Molecules that changed the world : a brief history of the art and science of synthesis and its impact on society. Weinheim: Wiley-VCH, 2008.

17. PEÑA TORREA, F.: El servicio de farmacia del Ejército Nacional durante la Guerra de Liberación. Su organización, funcionamiento y enseñanzas que se deducen, Madrid, 1941.

18. PITA FERNÁNDEZ, R. L.: A Real Casa da Moeda de Xubia: breve historia catálogo das súas cuñacións, Santiago de Compostela, Tórculo Edicións, 1996.

19. RODRÍGUEZ NOZAL, R. «Orígenes, desarrollo y consolidación de la industria farmacéutica española», Asclepio - Vol. LII-1-2000, p.142.

20. RODRÍGUEZ NOZAL, R. y GONZÁLEZ BUENO, A. Entre el arte y la técnica. Los orígenes de la fabricación industrial del medicamento. Madrid, 2005.

21. ROLDÁN Y GUERRERO, R.: La farmacia y los farmacéuticos militares en la guerra de liberación de España, Madrid, 1953.

22. ROLDÁNY GUERRERO, R.: Diccionario Biográfico y Bibliográfico de autores farmacéuticos españoles, Madrid: Real Academia de Farmacia, 1958-1976. Vols. I-IV.

\section{PUBLICACIONES PERIÓDICAS}

- $A B C$, Sevilla, 1900-1940.

- Boletín Oficial de la Junta de Defensa Nacional, Burgos, 1936-1939.

- El Compostelano, Santiago de Compostela, 1920-1946.

- Gaceta de Madrid, Madrid, 1900-1940.

- La Voz de la Farmacia, Madrid, 1930-1936.

- Revista de Farmacia, Santiago de Compostela, 1913-1936.

\section{FUENTES ARCHIVÍSTICAS}

- AFF: Archivo de la Facultad de Farmacia de Santiago.

Libro de registros de derechos de examen de la Facultad de Farmacia (1930-1936).

- AGMS: Archivo Militar General de Segovia.

Hojas de Servicios.

MAIZ ELEIZEGUI, Luis. Sección 1, Legajo M-188.

VILARIÑO DE ANDRÉS MORENO, Eduardo. Sección 611, legajo B-388.

- AHUS: Archivo Histórico Universitario de Santiago.

Expedientes personales:

FERNÁNDEZ RODRÍGUEZ, Ma Teresa. Legajo 415, expediente 1.

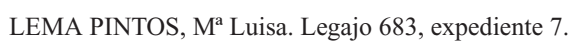

PEREIRA RODRÍGUEZ, Eugenia. Legajo 1044, expediente 16.

PÉREZ MOREIRAS, Celsa. Legajo 1069, expediente 20.

TOURIÑO MARTÍNEZ, Juan Benito Norberto. Legajo 1469, Expediente 6.

VAAMONDE FERNÁNDEZ, Ramona. Legajo 1487, expediente 15.

\section{FUENTES ORALES}

POCH Y DÍAZ DE RÁBAGO, María Asunción. Entrevista grabada el 20 de diciembre de 2007.

VILLAR BLANCO, Concepción. Entrevista grabada el 6 de noviembre de 2007).

\section{OTRA DOCUMENTACIÓN}

- Exposición Pioneiras. Mulleres empresarias galegas. Santiago de Compostela, Centro Sociocultural e Xuvenil «O Ensanche», 1-15 octubre 2008.

- Pharmakoteka: base de datos de medicamentos antiguos de la Universidad de Barcelona, disponible en http://www.ub.edu/crai/pharmakoteka/index.php

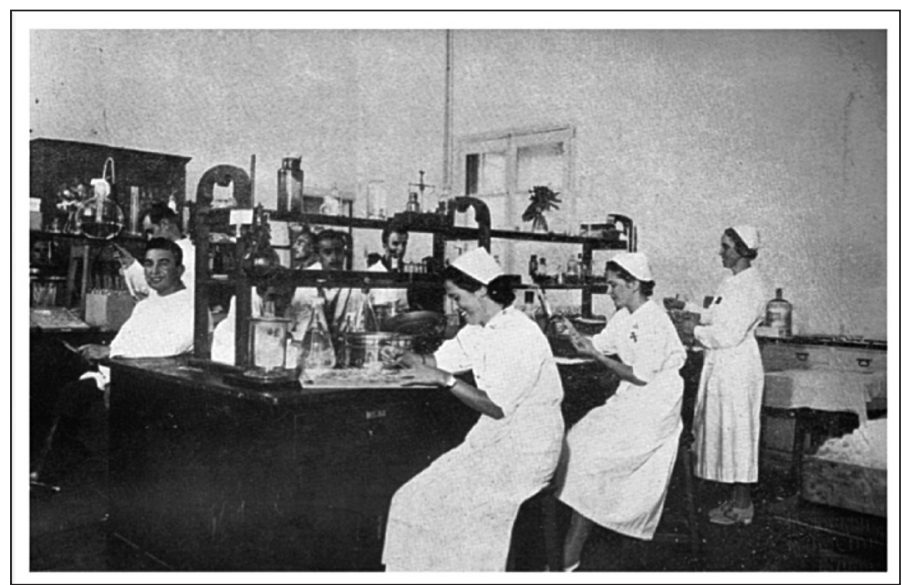

Figura 1. Sección de inyectables. Jóvenes voluntarios y voluntarias preparando ampollas inyectables. 


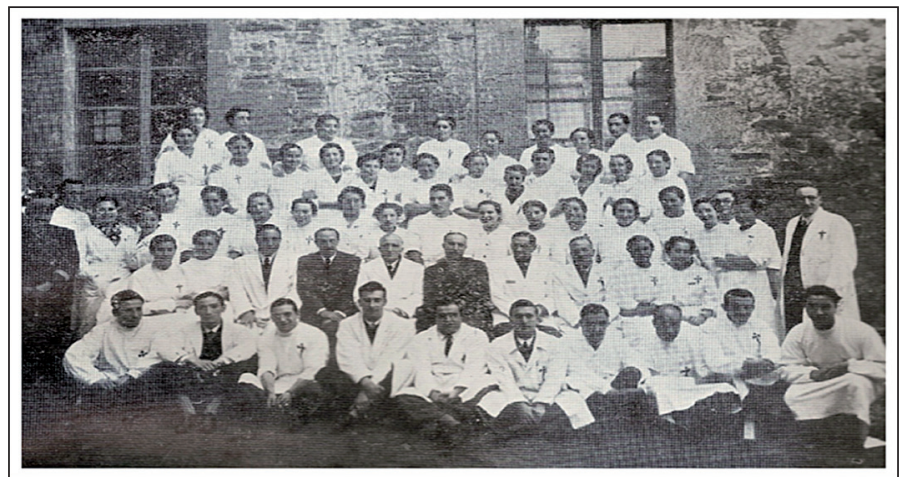

Figura 2. Plantilla inicial del Laboratorio de Farmacia Militar. En el centro, sentado en la segunda fila, aparecen el decano Eleizegui y el director del Laboratorio, Luís Maiz, escoltado por una autoridad militar ${ }^{65}$. Entre los profesores que aparecen en esta fila tenemos a José Lema Trasmonte, Carlos Puente Sánchez y Eduardo Vilariño. Detrás, justo en el centro está Juan «Juanito» Touriño ${ }^{66}$, un joven recién licenciado en Medicina que, según Marita Poch y Concepción Villar era «el alma del Laboratorio, organizaba muchísimo».

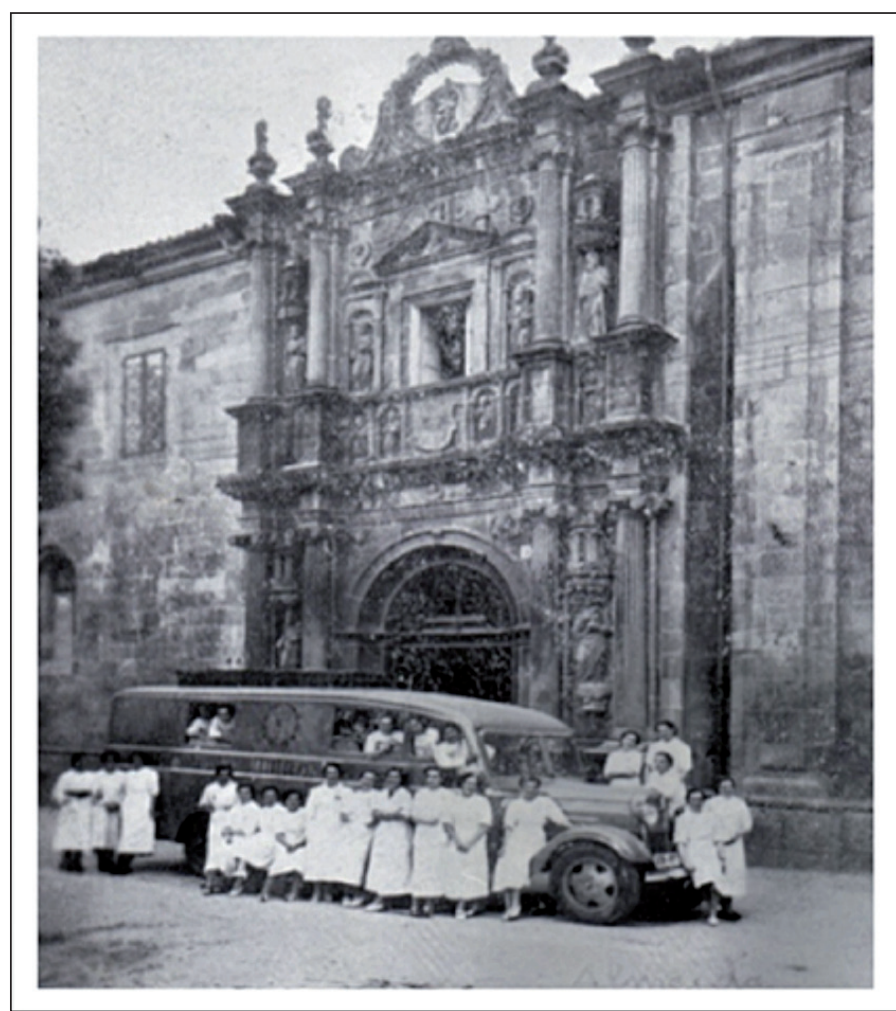

Figura 3. Farmacia móvil modelo «Santiago de Compostela» frente a la Facultad de Farmacia. Varias de las jóvenes voluntarias del Laboratorio de Farmacia Militar posan para la foto en verano de 1937.

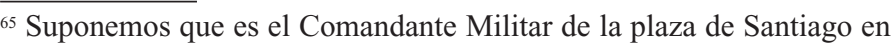
aquel momento, el teniente coronel Francisco Judel Peón que, nombrado para el cargo el 31 de julio de 1936, permaneció en dicho puesto durante toda la guerra civil.

${ }^{66}$ Juan Benito Norberto Touriño Martínez nació en Marín en 1913. Hijo de farmacéutico, estudió la carrera de Medicina en Santiago y había realizado el depósito para la obtención del título el 12 de junio de 1936. Desconocemos la razón por la que no se incorporó a filas. Permaneció los tres años de la guerra en el Laboratorio de Farmacia Militar, colaborando en labores de trabajo y organización. AHUS, Fondo Universitario, Expedientes personales, Leg.1469, Exp.6.
}

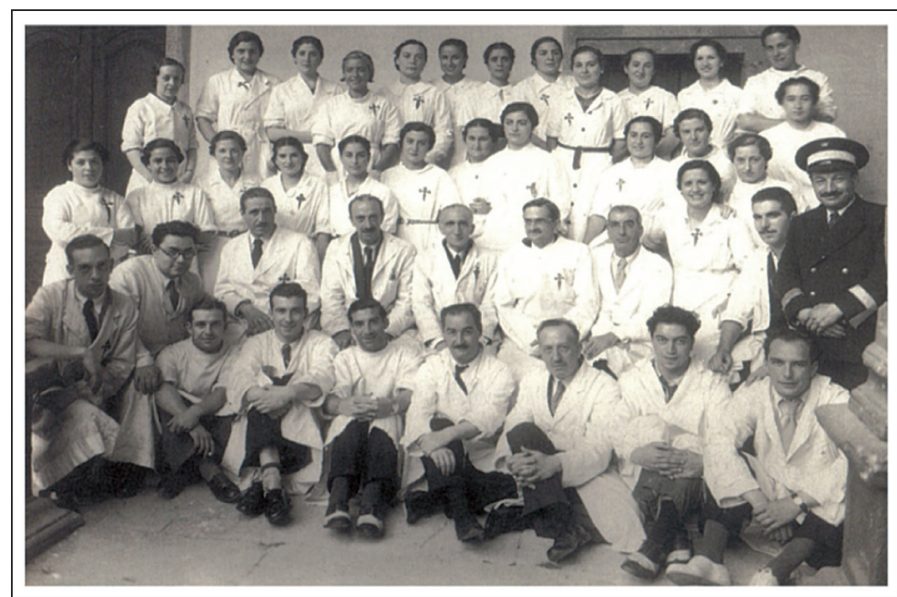

Figura 4: Personal del Laboratorio de Farmacia Militar en sus inicios.

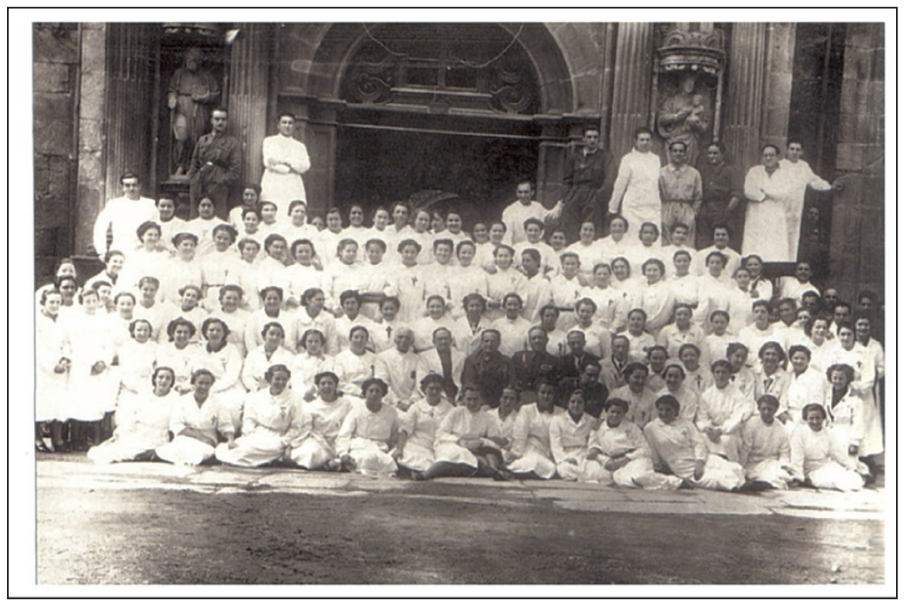

Figura 5. Fotografia del personal del Laboratorio de Farmacia Militar a las puertas de Fonseca. No conocemos con certeza la fecha en la que se tomó esta fotografía, pero es probable que se trate del primer aniversario del centro (agosto de 1937) puesto que aún está presente el profesor Vilariño de Andrés-Moreno vestido de militar (en la segunda fila, en el medio) que partiría posteriormente al frente de una farmacia móvil de campaña.
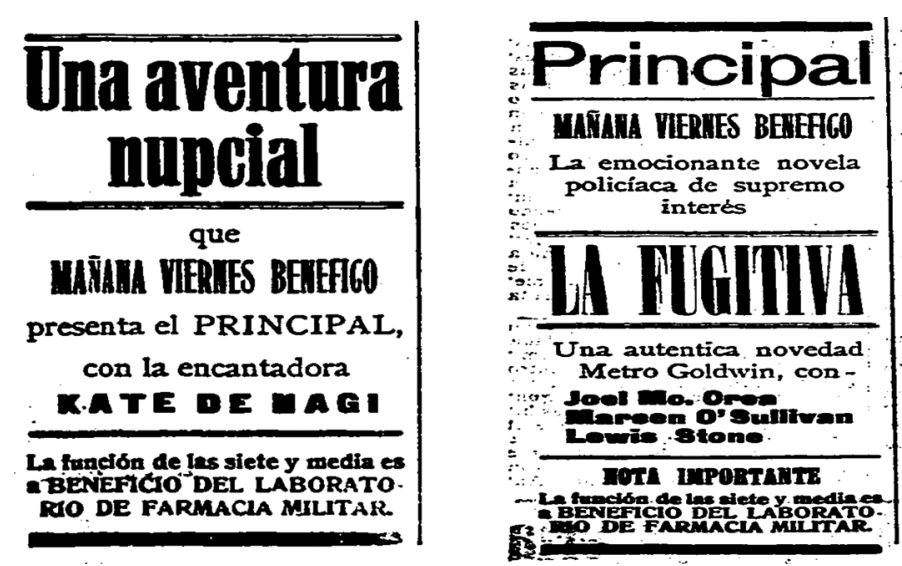

Figura 6. Estos son algunos de los anuncios de las películas proyectadas en el Teatro Principal cuya recaudación en taquilla iba a beneficio del Laboratorio de Farmacia Militar, aparecidos en El Compostelano el 28 de enero de 1937 y el 11 de febrero del mismo año, respectivamente. 


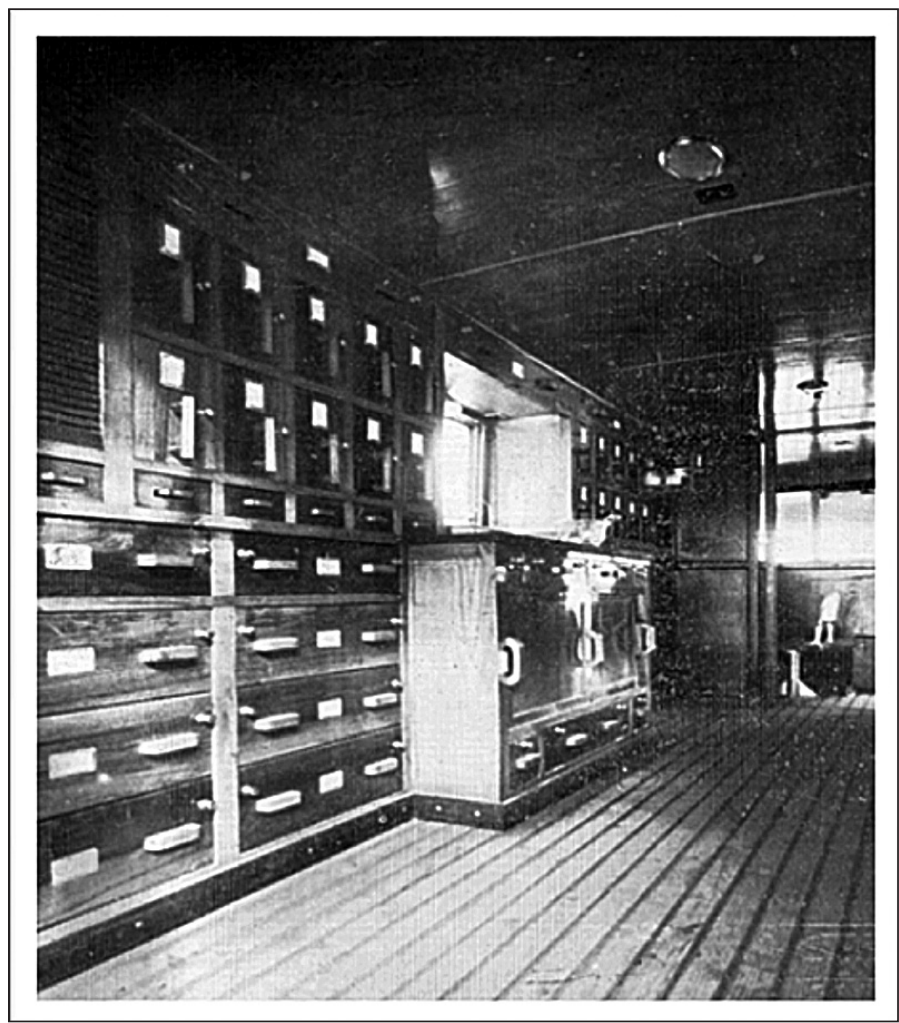

Figura 7. Interior de la farmacia móvil «Santiago de Compostela».

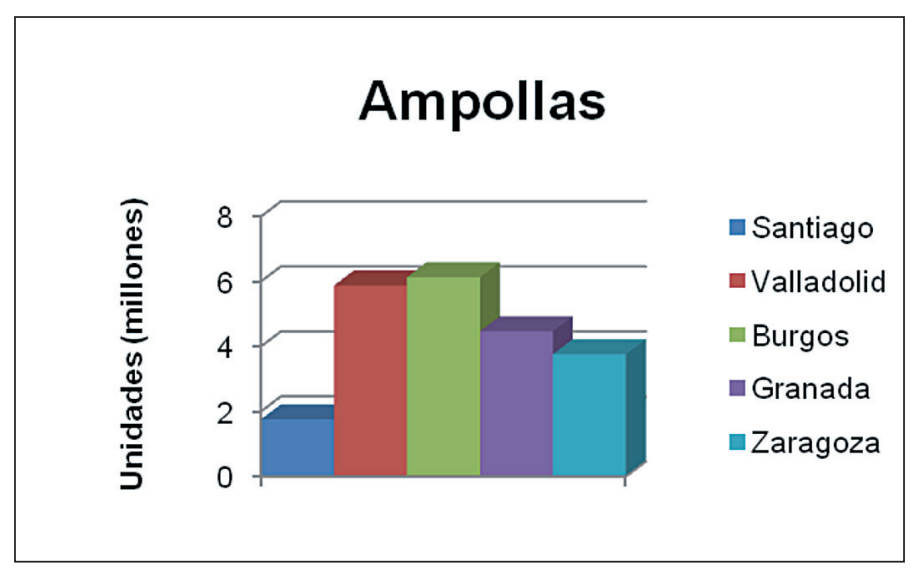

Figura 8. Producción de ampollas inyectables.

\section{Paquete de cura individual}

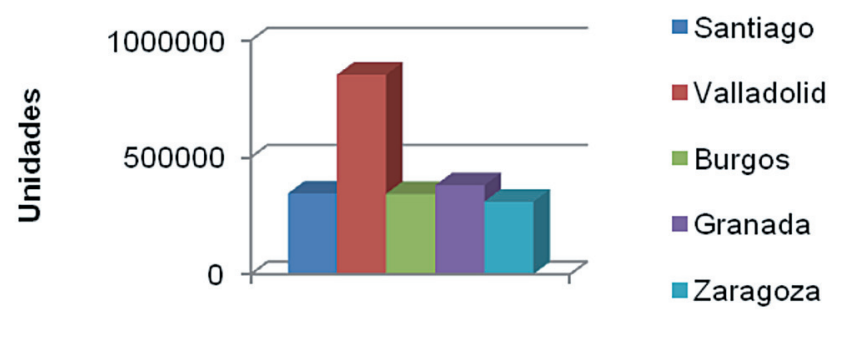

Figura 9. Producción de paquete de cura individual

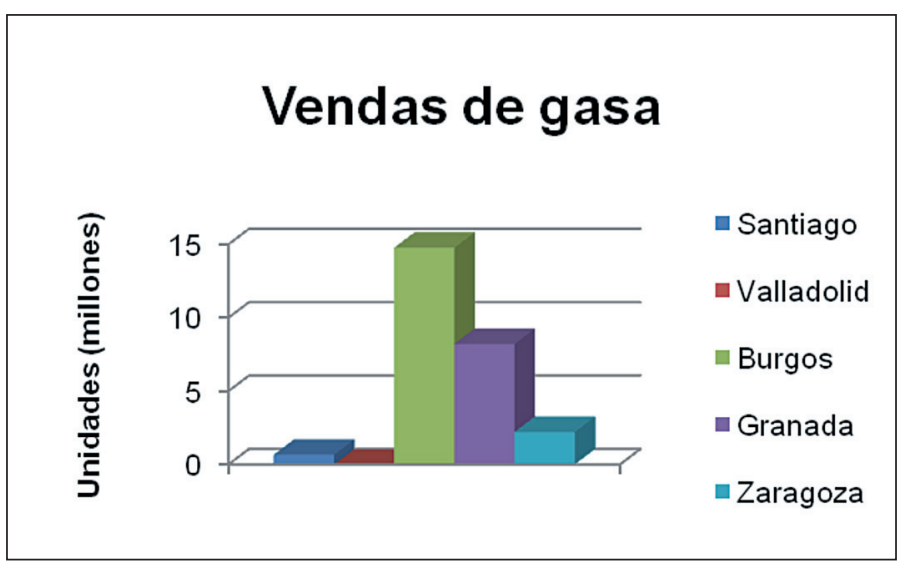

Figura 10. Producción de vendas de gasa 